\title{
Multivariate shift testing for hydrological variables, review, comparison and application
}

\author{
F. Chebana ${ }^{1 *}$
}

M.-A. Ben Aissia ${ }^{1}$

T. B. M. J. Ouarda ${ }^{1,2}$

${ }^{1}$ Statistical Hydroclimatology Research Group, 490, Rue de la Couronne, Quebec, Qc, Canada, G1K 9A9.

${ }^{2}$ Institute Center for Water and Environment (iWATER)

Masdar Institute of Science and Technology,

PO Box 54224, Abu Dhabi, UAE.

* Corresponding author: fateh.chebana@ete.inrs.ca

February 2017 


\section{Abstract}

Hydrological frequency analysis (HFA) is commonly used for the assessment of the risk

3 associated to hydrological events. HFA is generally based on the assumptions of homogeneity,

4 independence and stationarity of the hydrological data. Hydrological events are often described

5 through a number of dependent characteristics, such as peak, volume and duration for floods.

6 Unfortunately, in this multivariate setting, the verification of the above assumptions is often

7 neglected. When a shift occurs in a data series, it can affect the stationarity and the homogeneity

8 of the data. The objective of this paper is to study tests for shift detection in multivariate

9 hydrological data. The considered shift tests are mainly based on the notion of depth function,

10 except for one test that is considered for comparison purposes. A simulation study is performed to

11 evaluate and compare the power of all these tests with hydrological constraints. A flood analysis

12 application is also carried out to show the practical aspects of the considered tests. The power of

13 the considered tests is influenced by a number of factors, including the sample size, the shift

14 amplitude, the magnitude of the series and the location of the shift in the series.

15

16 Keywords: shift, hypothesis testing, multivariate, stationarity, homogeneity, flood, depth. 
19 In general, in order to perform the statistical analysis of hydrological data a number of fundamental

20 assumptions are required. More precisely, preliminary testing for stationarity, homogeneity and

21 independence is a necessary step in any hydrologic frequency analysis (HFA) study [e.g. Rao and

22 Hamed, 2000]. One or more of these assumptions can fail because of a number of reasons. For

23 instance, the assumption of stationarity may not be verified because of a regime shift that can be

24 due to an abrupt change in the watershed characteristics caused by natural or anthropogenic actions

25 on the physical environment, such as deforestation or the construction of a hydraulic structure [e.g.

26 Bobée and Ashkar, 1991; Burn and Hag Elnur, 2002, Ouarda and El-Adlouni, 2011]. Because of

27 the growing evidence concerning climate change, the common assumption of stationarity of

28 hydrologic phenomena may no longer hold. The presence of shifts in data series is highlighted in

29 several hydrometeorological studies, such as floods [Seidou and Ouarda, 2007], precipitation

30 [Beaulieu et al., 2008, 2010; Ouarda et al., 2014; Chen et al., 2016], low-flows [Ehsanzadeh et al.,

31 2011], wind speed [Naizghi and Ouarda, 2016], and temperature data [Jandhyala et al., 2014].

32 The analysis of multivariate events is of particular interest in several applied fields, including

33 hydrology. Indeed, complex hydrological events, such as floods, droughts and storms are

34 multivariate events characterized by a number of correlated variables. For instance, volume ( $V)$,

35 peak $(Q)$ and duration $(D)$ describe floods [Ouarda et al., 2000; Shiau, 2003; Yue et al., 1999]. The

36 use of univariate HFA can lead to inaccurate estimation of the risk associated to a given event.

37 Recently, several studies adopted the multivariate framework to treat extreme hydrological events,

38 see e.g. [Chebana, 2013] for a summary and recent references.

39 HFA is composed of four main steps: i) descriptive and explanatory analysis, ii) verification of the

40 basic assumptions including stationarity, homogeneity and independence, iii) modeling and 
41 estimation, and iv) risk evaluation and analysis. In the univariate setting, these steps are extensively

42 treated [e.g. Rao and Hamed, 2000]. In the multivariate context, the first two steps (i and ii)

43 attracted considerably less attention than the two others. For an overview of step i) in the

44 multivariate framework, the reader is referred to Chebana and Ouarda [2011]. Checking the basic

45 assumptions (step ii) is generally ignored in the hydrological literature in the multivariate setting.

46 For instance, it is not treated in Kao and Govindaraju [2007], Song and Singh [2009] and

47 Vandenberghe et al. [2010]. This step has a significant impact on steps iii) and iv). Therefore,

48 ignoring step ii) may lead to inaccurate models and hence to wrong results and inappropriate

49 decisions regarding resource management and infrastructure design. In order to avoid the loss of

50 human lives and property associated with design event underestimation, or the increase in

51 construction cost associated with overestimation, it is necessary to treat step ii) for a sound and

52 complete multivariate HFA.

53 Non-stationarity is a very wide notion and includes in particular the presence of one or several

54 shifts in the data. Recently, Chebana et al. [2013] provided a review and application of multivariate

55 nonparametric tests for monotonic trends and presented approaches that can be considered as a

56 preliminary step in a complete multivariate HFA. Chebana et al. [2013] indicated that, for

57 multivariate hydrological data, various types of non-stationarities can be found for which

58 appropriate tests should by reviewed, compared and applied.

59 The available literature on shift detection in the hydrological context is focused on the univariate

60 setting. Nevertheless, statistical literature exists for the general multivariate setting. Hence, existing

61 comparisons and evaluations of the proposed tests are based on scenarios and hypotheses that are

62 not adapted to the hydrological context (e.g. sample size, scale, and distributions). In addition, these

63 comparative studies are not exhaustive and are often not based on quantifiable performance criteria. 
64 Consequently, there is a need for comparative studies that consider all available tests and are 65 representative of hydrological reality, scale and constraints.

66 Several multivariate shift tests are based on the concept of depth function. The latter is a statistical 67 notion to measure the depth (or its opposite, the outlyingness) of a given point with respect to a 68 multivariate data cloud or its underlying distribution. Depth functions were developed in the 69 seventies and have been receiving increasing interest [e.g. Tukey, 1975; Liu, 1990; Zuo and 70 Serfling, 2000; Mizera and Müller, 2004; Zuo and Cui, 2005; Lin and Chen, 2006; Liu and Singh, 71 2006; Chebana and Ouarda 2011; Singh and Bárdossy, 2012; Lee et al., 2014; Wazneh et al.,

72 2013; 2015]. Depth functions provide a scale-standardized measure of the position of any data 73 point relative to the center of the distribution due to its affine-invariant property [ Li and Liu, 2004].

74 For the location shift, this property allows us to view the depth-based test statistics as scale75 standardized measures. Therefore, depth-based tests can be performed without the difficulty of 76 estimating the variance of the null sampling distributions. Instead, the decision rule is derived by 77 obtaining $\mathrm{p}$-values using the idea of permutation.

78 The objectives of the present paper are: 1) to show the importance of the testing step in a 79 multivariate HFA, in particular shift testing, 2) to review shift tests that are available in the 80 statistical literature and which are applicable to hydrological variables within the multivariate HFA 81 context, and 3) to perform an overall evaluation and comparison of these tests under hydrological 82 constraints (such as short sample size, specific distributions).

83 This paper is organized as follows. Section 2 introduces the definitions and notations related to the 84 shift concept. The considered tests are described in Section 3. The simulation study to evaluate the 85 performance of these tests is presented in Section 4. Section 5 illustrates an application of the 86 reviewed tests on hydrological data. The conclusions of the study and a number of perspectives are 87 reported in Section 6. 


\section{Shift concept}

89 A shift can be defined by the date at which at least one feature of a statistical model (e.g., location,

90 scale, intercept and trend) undergoes an abrupt change [Seidou et al., 2007]. A large number of

91 techniques can be found in the literature to identify the date of a potential shift and to check its

92 significance. Most of the methodologies use statistical hypothesis testing to detect shifts in the

93 slope or intercept of linear regression models [Easterling and Peterson, 1995; Vincent, 1998; Lund

94 and Reeves, 2002]. For instance, Solow [1987], Easterling and Peterson [1995], Vincent [1998],

95 Lund and Reeves [2002] and Wang [2003] used the Fisher test to compare a model with and without

96 a shift. The Student and Wilcoxon tests can also be applied sequentially to detect shifts in data

97 series [Beaulieu et al., 2007, 2008].

98 Note that not all shift approaches are based on hypothesis testing. For instance, Wong et al. [2006]

99 used the grey relational method [Moore, 1979; Deng, 1989] for single shift detection in stream flow

100 data series. In some rare cases, curve fitting methods were used [e.g. Sagarin and Micheli, 2001;

101 Bowman et al., 2006]. Extensive reviews of shift detection and correction methodologies in

102 hydrology and climate sciences can be found in Peterson et al. [1998] and Beaulieu et al. [2009].

103 To define a shift, let $\left(x_{i}\right)_{i=1, \ldots, n}$ be a given $d$-variate dataset and $1<s<n$ be a possible shift. If such

$104 s$ exists, the series is divided into two subsamples with sizes $s$ and $m=n-s$ such that:

105

$$
\begin{aligned}
& \left(y_{1}, \ldots, y_{s}\right)=\left(x_{1}, \ldots, x_{s}\right) \\
& \left(z_{1}, \ldots, z_{m}\right)=\left(x_{s+1}, \ldots, x_{n}\right)
\end{aligned}
$$

106 Denote by $G_{1}$ and $G_{2}$ respectively the cumulative distribution functions of these two subsamples.

107 The two distributions $G_{1}$ and $G_{2}$ have the same form, except for the location, i.e. $G_{1}(x)=G_{2}(x+\boldsymbol{\delta})$ 
108 for all $x \in R^{d}$ where $\boldsymbol{\delta} \in R^{d}$ is a constant vector. Consequently, when testing the presence of a shift

109 at a position $s$ of the series $\left(x_{i}\right)_{i=1, \ldots, n}$, the null and alternative hypotheses are respectively:

$110 H_{0}: \boldsymbol{\delta}=0$ i.e. there is no location shift

$111 H_{1}: \boldsymbol{\delta} \neq 0$ i.e. there are two different subsamples at least in one component of $\boldsymbol{\delta}$.

\section{3. The considered tests}

113 In the present paper, several tests to detect a shift in the location of multivariate series are

114 considered. Except for the C-test, all the presented tests are based on depth functions. The C-tests

115 is considered for comparison purposes. More details are given below regarding p-value evaluation.

116 Table 1 presents a summary of the tests considered in this study.

\section{3.1. Depth functions}

118 The absence of a natural order for multivariate data led to the introduction of depth functions

119 [Tukey, 1975]. They are developed and used in a number of research fields, e.g. in statistics by

120 Mizera and Müller, [2004] and Ghosh and Chaudhuri [2005], in economics and social sciences by

121 Caplin and Nalebuff [1991a; b], in industrial quality control by Liu and Singh [1993] and in water

122 sciences by Chebana and Ouarda [2008]. A detailed description and review of depth functions can

123 be found in Zuo and Serfling [2000]. In the following we present a very brief overview of the main

124 concepts. For a given cumulative distribution function $F$ on $\mathfrak{R}^{d}(d \geq 1)$, a depth function can be

125 defined. It is any non-negative bounded function which possesses a number of suitable properties,

126 i.e. Affine invariance, Maximality at center, Monotonicity relative to the deepest point, Vanishing

127 at infinity. 
128 A number of depth functions have been developed and studied [Zuo and Serfling, 2000]. In the

129 following, we present some of the key ones which are considered in this study:

130 1. Tukey (or Halfspace) depth : for $x \in R^{d}$ with respect to a probability $P$ on $R^{d}$, it is defined as:

$$
T D(x ; P)=\inf \{P(H): H \text { a closed halfspace that contains } x\}
$$

132 Chebana and Ouarda [2011] presented a simple illustration of the computation of this depth

133 function.

134 2. Mahalanobis depth: for a given distribution $F$ on $R^{d}$ with $\mu$ and A any corresponding location 135 and covariance measures, respectively, it is given by:

$$
M D(x ; F)=\frac{1}{1+d_{A}^{2}(x, \mu)}
$$

137 where $d_{A}^{2}(x, y)=(x-y)^{\prime} A^{-1}(x-y)$ is the Mahalanobis distance between points $x, y \in R^{d}$ given 138 a positive definite matrix $A$.

139 3. Simplicial depth: it is expressed as:

$$
S D(x ; P)=P\left\{x \in S\left[X_{1}, \ldots, X_{d+1}\right]\right\}
$$

141 where $S\left[X_{1}, \ldots, X_{d+1}\right]$ is the random $d$-dimensional simplex with vertices $X_{1}, \ldots, X_{d+1}$ which is a 142 random sample from the distribution $P$.

143 By replacing $F$ with a suitable empirical function $\hat{F}_{n}$, a corresponding sample version of a 144 statistical depth function $D(x ; F)$ may be defined and denoted by $D_{n}(x)=D\left(x ; \hat{F}_{n}\right)$. Its asymptotic 145 properties have been studied, for instance, in Liu [1990], Massé [2002; 2004] and Lin and Chen 146 [2006]. The computation of some depth functions is complex, especially for high dimensions, and 147 requires approximations and specific algorithms, see for instance, Miller et al. [2003] and Massé 148 and Plante [2009]. 
149 In principle, each depth-based test can be defined using any available depth function. However,

150 some of these tests were originally defined and their properties are studied on the basis of a specific

151 depth function. Even though the problem and the tests can be defined in any dimension, the

152 simulation study is based on the bivariate case. The obtained results and conclusions cannot be

153 directly extended and generalized.

\section{3.2. Description of tests}

155 In this section, the considered multivariate shift detection tests are described as well as the method

156 to evaluate their p-values. Performance comparison of these tests in the literature is also presented.

\section{The C-test (Cramér test)}

158 The Cramér test is a two-sample test proposed by Baringhaus and Franz [2004]. It is a

159 generalisation of the univariate test proposed by Cramér [1928]. However, it is more appropriate

160 to detect shifts in location. This test is based on the difference of Euclidian distances between the

161 observations of the two different subsamples and the half sum of all Euclidian distances of

162 observations of the same subsample. The corresponding test statistic is given by:

$$
C=\frac{s m}{s+m}\left[\frac{1}{s m} \sum_{i=1}^{s} \sum_{j=1}^{m}\left\|y_{i}-z_{i}\right\|-\frac{1}{2 s^{2}} \sum_{i, j=1}^{s}\left\|y_{i}-y_{j}\right\|-\frac{1}{2 m^{2}} \sum_{i, j=1}^{m}\left\|z_{i}-z_{j}\right\|\right]
$$

164 where $\left\|y_{i}-z_{j}\right\|$ is the Euclidian distance between the $i^{\text {th }}$ observation of the first subsample and the

$165 j^{\text {th }}$ observation of the second subsample. Recall that $s$ is the location of the shift (and hence the size

166 of the first subsample) and $m=n-s$ is the size of the second subsample.

167 The null hypothesis $H_{0}$ is rejected for large values of $C$. A large value of $C$ means that the distance

168 between the observations of the two subsamples is large and consequently, the two subsamples are

169 different. To calculate the p-value, the bootstrapping method is used. 


\section{The M-test (Monitoring the Maximum Depth Points)}

171 According to $\mathrm{Li}$ and Liu [2004], the deepest point of a distribution is a location parameter.

172 Consequently, if $G_{1}$ and $G_{2}$ are identical distributions, they would have the same deepest point,

173 that is, the deepest points $\theta_{G_{1}}$ and $\theta_{G_{2}}$ should be the same. In addition, for a given depth function $D$,

174 we have $D_{G_{2}}\left(\theta_{G_{1}}\right)=D_{G_{1}}\left(\theta_{G_{2}}\right)$. If there is an important change in location, $\theta_{G_{1}}$ and $\theta_{G_{2}}$ would be

175 different and $\theta_{G_{2}}$ would be located far away from the subsample from $G_{1}$ for which the depth value

$176 D_{G_{1}}\left(\theta_{G_{2}}\right)$ with respect to $G_{1}$, is smaller, and vice-versa. Based on this idea, Li and Liu [2004]

177 proposed the statistic:

$178 \quad M=\min \left\{D_{G_{2}}\left(\theta_{G_{1}}\right), D_{G_{1}}\left(\theta_{G_{2}}\right)\right\}$

179 Li and Liu [2004] used the simplicial depth function SD (6), but other depth functions can be used.

180 Indeed, Li and Liu [2004] suggested the Mahalanobis depth function MD (5) for the elliptical

181 distribution. They specified that the SD and TD depth functions can be used with any distribution.

182 The null hypothesis $H_{0}$ is rejected for small values of $M$. To approximate the corresponding p-

183 value, Li and Liu [2004] proposed Fisher's permutation test [Snedecor and Cochran, 1967].

184 The T-test (Monitoring Shrinking Cusp Point)

185 Li and Liu [2004] described a graphical approach called DD-plot (for depth-depth) to compare the 186 location of two subsamples. In the context of the T-test, a DD-plot consists in plotting (D)

$187\left(D_{G_{1}}(x), D_{G_{2}}(x)\right)$ with $x$ being from either subsample. When the two subsamples follow exactly

188 the same distribution, the DD-plot is a diagonal line that passes through the origin as illustrated in

189 Figure 1a. However, if there is a location change, the graph has a form of leaf with its tip pointing 190 toward the origin (Figure 1b). The more important the location change is; the closer the tip will be 
191 to the origin (Figure 1c). The T-test is based on an approximation of the distance between the tip

192 and the origin of the DD-plot. We define the set of points:

$193 \Omega=\left\{x_{i} \mid i \in\{1, \ldots, n\}\right.$, there is no $x_{j}: D_{G_{1}}\left(x_{j}\right) \geq D_{G_{1}}\left(x_{i}\right)$ and $\left.D_{G_{2}}\left(x_{j}\right) \geq D_{G_{2}}\left(x_{i}\right)\right\}$

194 Then we find the point $x_{\min }$ of $\Omega$ such that:

195

$\left|D_{G_{1}}\left(x_{\min }\right)-D_{G_{2}}\left(x_{\min }\right)\right|=\min _{x \in \Omega}\left|D_{G_{1}}(x)-D_{G_{2}}(x)\right|$

196 If there are several points $x_{\min }$, we take the mean of the corresponding coordinates. The point

197 identified by (10) is an approximation of the leaf-tip point of the DD-plot. The test statistic is then

198 given by:

$199 T=\left(D_{G_{1}}\left(x_{\min }\right)+D_{G_{2}}\left(x_{\min }\right)\right) / 2$

200 Even though, the distance of the leaf-tip to the origin is approximately $\sqrt{2} T$, the use of the statistic

$201 T$ is equivalent. Similarly to the M-test, Li and Liu [2004] used the SD function (6) for the T-test.

202 However, MD (5) and TD (4) depths can also be used. The p-value is obtained using the Fisher's

203 permutation test.

204 The W-test (Wilcox test)

205 The W-test was developed by Wilcox [2005]. Similarly to the M-test, the W-test is based on the

206 idea that under the null hypothesis, the medians of the two subsamples must be similar. To define

207 the W-test statistic, first the difference of each component is calculated

$208 d_{i j}^{(u)}=z_{i}^{(u)}-y_{j}^{(u)}, u=1, \ldots, d ; i=1, \ldots, s ; j=1, \ldots, m$ to constitute the vector $d_{i j}=\left(d_{i j}^{(1)}, \cdots, d_{i j}^{(d)}\right)$.

209 Wilcox [2005] defined the test statistic by:

210

$W=D_{F}(\mathbf{0}) / \max _{i=1, \ldots, s ; j=1, \ldots, m} D_{F}\left(d_{i j}\right)$ 
211 where $F$ is the distribution of the set of vectors $d_{i j}$ and $D$ is the TD depth function (4). Under the

212 null hypothesis, we have $W=1$, whereas under the alternative hypothesis, we have $\mathrm{W}<1$. The

213 asymptotic distribution of $W$ is unknown. However, Wilcox [2005] proposed some critical values

$214 C_{\alpha}$ for significance levels $\alpha=0.01 ; 0.025 ; 0.05 ; 0.10$. The values of $C_{\alpha}$ are derived empirically

215 from simulations using a least squares regression method, and under the assumption of normality.

216 The null hypothesis is rejected when $W$ is lower than $C_{\alpha}$.

217 The QIA- and QIB-tests (quality index tests)

218 Liu and Singh [1993] developed a Wilcoxon-type rank test based on data depth. This test can detect

219 a location shift and/or a positive scale shift. The statistic of this test is given by:

220

$Q_{a}=\frac{1}{n} \sum_{i=1}^{m} \#\left\{y \in\left\{y_{1}, \cdots, y_{s}\right\}: D_{G}(y) \leq D_{G}\left(z_{i}\right)\right\}$

221 Under the null hypothesis, $Q_{a}=0.5$ whereas if there is a shift in location, then $Q_{a}<0.5$. Liu and

222 Singh [1993] used MD (5). Zuo and He [2006] found that under some regularity conditions, the

223 asymptotic distribution of $Q_{a}$ calculated with MD (5), TD (4) or projection depth is normal

$224 N\left(\mu, \sigma^{2}\right)$ with mean $\mu=0.5$ and variance $\sigma^{2}=\left(s^{-1}+m^{-1}\right) / 12$. In the present study, the

225 asymptotic (QIA-test) and bootstrap (QIB-test) methods are used to evaluate the $p$-values.

226 The Z-test (Zhang test)

227 Zhang et al. [2009] developed a new test based on the statistic $Q_{a}(13)$ where the statistic of the Z-

228 test is given by:

$229 \quad Z=\frac{6}{n} s \times m\left(Q_{a}-0.5\right)^{2}$

230 To define Z, Zhang et al. [2009] used MD (5). To find the asymptotic distribution of $Z$, we define

231 the matrix $A$ : 
$232 A=\left[\begin{array}{cc}1-p_{1} & \sqrt{p_{1} p_{2}} \\ \sqrt{p_{1} p_{2}} & 1-p_{2}\end{array}\right]$

233 where $p_{i}=\frac{n_{i}}{n}, i=1$ or 2 and $n_{i}$ is the number of observations in the $i^{\text {th }}$ subsample. Let $r$ be the

234 rank of $A$, and the nonzero eigenvalues of $A$ are denoted by $\lambda_{1}, \ldots, \lambda_{r}$. Under $H_{0}, Z$ follows

235 asymptotically a sum of independent chi-square distributions:

$236 \quad Z \approx \lambda_{1} \chi^{2}(1)+\lambda_{2} \chi^{2}(1)+\ldots+\lambda_{r} \chi^{2}(1)$

237 This relation is also valid for the half-space and projection depth functions. The asymptotic method 238 is used to evaluate the corresponding $p$-value.

239 3.3. The p-value computation

240 The $p$-value of a given test is a simple criterion commonly used by practitioners to decide for the 241 acceptance or rejection of a target null hypothesis. The p-value is based on the distribution of the 242 statistics of the underlying test. For some of the considered tests in the present study, the asymptotic 243 or the exact distribution of the test statistic is unknown or difficult to obtain. Consequently, 244 approximations of the distribution of test statistics, under the null hypothesis, are required. To this 245 end, resampling methods are used. In the present paper, a permutation method [Snedecor and 246 Cochran, 1967] and a bootstrap method are used. They are briefly described below. More details 247 can be found, for instance, in Good [2005].

248 To apply the permutation method, the observations should be exchangeable, i.e. the observations

249 should be independent and identically distributed [see e.g. Efron and Tibshirani, 1994]. This 250 method consists in permuting $n_{p}$ times the sample $\left(x_{i}\right)_{i=1, \ldots, n}$ without replacement where $n_{p}$ is a large 251 number. For each permuted sample, the $s$ first elements constitute the first subsample and the 252 remaining ones constitute the second subsample. The test statistic, generically denoted by $S$, is 
253 calculated for each permutation $\left(S_{i, i=1, \ldots, n_{p}}^{*}\right)$. The null hypothesis should be rejected for small values

254 of the statistic. The p-value is the proportion of $\left(S_{i, i=1, \ldots, n_{p}}^{*}\right)$ smaller or equal to the value $S_{o b s}$

255 obtained from the original observed sample.

256 The bootstrap method is similar to the permutation method, except that the sample $\left(x_{i}\right)_{i=1, \ldots . n}$ is

257 resampled with replacement and the independence assumption is necessary [see e.g. Efron and

258 Tibshirani, 1994].

259 3.4. Review of comparative studies

260 Some performance comparisons of the above tests are presented in the literature. The M- and T-

261 tests, given respectively in (8) and (11), were compared to the Hotelling [1947] $T^{2}$ test by Li and

262 Liu [2004]. The Hotelling's $T^{2}$ test is the most frequently used parametric test to detect location

263 shift [e.g. Ye et al., 2002]. For normally distributed samples with unit variances, the powers of

264 these three tests were found to be comparable, whereas for samples with Cauchy distribution with

265 the same parameter, the M- and T- tests were shown to be more powerful than the Hotelling's test.

266 Moreover, in this case, the M-test outperformed the T-test. Note that both considered distributions

267 (normal and Cauchy) are symmetric. In order to evaluate the performance of these tests for skewed

268 distributions, Dovoedo and Chakraborti [2015] considered ten distributions belonging to five well-

269 known families of multivariate skewed distributions.

270 Liu and Singh [2006] compared also the quality index test (13) to Hotelling's test. For normal

271 samples, the performances of the two tests were similar, while for Cauchy and Exponential samples

272 the quality index test outperformed the Hotelling's test. Baringhaus and Franz [2004] found that

273 the C-test (7) performs almost as well as Hotelling's test for normal and non-normal samples. 
274 These comparisons and evaluations are not appropriate for hydrological applications, since the

275 considered samples are not representative of the hydrological conditions where sample sizes are 276 generally short, and the variables mainly follow extreme distributions such as the Gumbel and the

277 Generalized Extreme Value (GEV) [e.g. El-Adlouni et al., 2010]. The Normal, Cauchy and t 278 distributions are not commonly used in multivariate HFA. In addition, in the literature, only partial

279 comparisons of the above tests were carried out and no overall comparison has been performed 280 dealing with all of them (to the best knowledge of the authors, the only references performing such 281 comparisons are those given in this section).

\section{Simulation study}

283 The objective of this simulation study is to evaluate and compare the performances of all the 284 previously presented tests in the hydrological context, such as in the case of flood series based on 285 flood peak $Q$ and volume $V$. We also adopt samples with small sizes such as commonly 286 encountered in hydrology.

\subsection{Adaptation to floods}

288 The previously presented tests can be applied to hydrological events such as floods, rain storms 289 and droughts. In this paper, we focus on floods. Floods can be described by their peak $Q$, volume $290 V$ and duration $D$, which can be correlated. Indeed, according for instance to Yue [2001] there is

291 generally a strong correlation between $Q$ and $V$, between $V$ and $D$ and a moderate correlation 292 between $Q$ and $D$. In the present paper, the above considered tests are used to detect location shifts 293 in $Q$ and $V$. These two variables are the most studied in hydrology for both the univariate and the 294 bivariate cases (see e.g. Chebana, 2013).

295 According to Sklar [1959], a bivariate distribution can be composed of marginal distributions and 296 a copula. Some previous studies showed that the $Q$ and $V$ series can be marginally fitted by a 
297 Gumbel distribution [Chebana and Ouarda, 2007; Shiau, 2003; Yue, 2001; Yue et al., 1999]. The

298 cumulative Gumbel distribution is given by:

$299 \quad F(x)=\exp \left\{-\exp \left(-\frac{x-\beta}{\sigma}\right)\right\}, x$ and $\beta$ real, $\sigma>0$

300 where $x$ plays the role of each of the variables $Q$ and $V$. The dependence between $Q$ and $V$ can be

301 represented by the Gumbel logistic model [e.g. Aissia et al., 2012; Chebana et al., 2009; Shiau,

302 2003; Yue et al., 1999], expressed according to the following copula:

303

$C_{b}(u, v)=\exp \left\{-\left[(-\log (u))^{b}+(-\log v)^{b}\right]^{1 / b}\right\}, b \geq 1$ and $0 \leq u, v \leq 1$

304 Note that $b=1 / \sqrt{1-\rho}$ where $\rho$ is the usual correlation coefficient [see e.g. Genest and Rivest,

305 1993; Gumbel and Mustafi, 1967].

306 The presented tests may be affected by several factors. In the simulation study, we examine the

307 impact of the record length $n$ (sample size) as well as the degree of change (shift amplitude) in each

308 component of the multivariate series.

309 For the simulation study, we generate samples $(Q, V)$ according to models (17) and (18). We

310 consider the Gumbel distribution as marginal for both $Q$ and $V$. The corresponding parameters are

311 denoted by:

$312-\sigma_{Q 1}$ and $\beta_{Q 1}$ for respectively the scale and location parameters for $Q$ of the first $s$ observations

313 (before the shift); and

$314-\sigma_{Q 2}$ and $\beta_{Q 2}$ for respectively the scale and location parameters for $Q$ after the shift.

315 We define similarly the parameters of $V\left(\sigma_{V}, \beta_{V}\right)$ and the parameter $b$ of the logistic Gumbel

316 copula. 
317 For the $G$ distribution before the shift, we selected the parameters of the Skootamatta basin in

318 Ontario (Canada) which are also employed for simulation studies by Chebana and Ouarda [2007;

319 2009]. Consequently, $\sigma_{Q 1}=15.85, \beta_{Q 1}=51.85, \sigma_{V 1}=300.22 \beta_{V 1}=1239.8$ and $b=1.414$. Due to

320 space limitations, the reader is referred to the above references for more details regarding the

321 Skootamatta basin.

322 We study the effect of the following two factors on the performance of the tests: the record length

323 ( $n$ : sample size) and the amplitude of shifts in the location parameters $\beta$, since the tests are mainly

324 designed to detect shifts in the location. Usually, the dependence parameter appears in the copula

325 whereas the location and scale parameters are present in the marginal distributions [Hobcek Haff et

$326 a$ al., 2010]. For location shift, we denote $G_{1}(x)=G_{2}(x+\delta)$ where $\delta=\left(\delta_{Q}, \delta_{V}\right)$ is the vector of the

327 shifts in the location of $Q$ and the location of $V$ respectively. In addition, the dependence level

328 between the two variables $Q$ and $V$ is considered with three dependence levels corresponding to $\rho$

$329=0.25$ (low), $\rho=0.50$ (moderate) and $\rho=0.75$ (high) where the associated copula dependence

330 parameter is respectively $b=1.155,1.414$ and 2.0.

331 Even though the considered tests and the simulations are presented in the bivariate setting, they

332 can also be defined when more than two variables are involved to characterize the phenomenon. In

333 theory, the concepts of these tests can be extended to higher dimensions. However, some technical

334 difficulties could arise. First, the computation of some depth functions (which is the basis of a

335 number of the above tests) is complex and requires approximations and specific algorithms for

336 higher dimensions (e.g. for the simplicial depth). Second, a number of issues that are related to

337 models (especially for copulas) such as uncertainty increase, effectiveness of goodness-of-fit

338 testing, model formula complexity and questionable representativety of some models, need to be

339 addressed. Third, the number of the shift possibilities increases rapidly with the dimension, for 
340 instance, with 3 variables we have 8 possibilities where the shift occurs without accounting for the

341 different shift amplitudes (for each variable) as well as the different types of dependence between

342 the variables ( 3 pairwise and 1 overall). Hence, the simulation results obtained in this paper cannot

343 be generalised directly to higher dimensions, and additional work will be required for this purpose.

\section{4.2. Simulation design}

345 The conducted simulation study consists of two steps. In the first one, we generate a large number

$346 N$ of samples to evaluate the effects of different factors on the performance of the tests. Three

347 sample sizes are considered $n=30,50$ and 80 corresponding to $s=5,10 ; 5,10,20$ and 5, 10, 20,

34830 respectively. For each sample size, several amplitudes of location shift are considered: $\delta=10$,

$34920,-20,40$ and $70 \%$. We generate the samples as follows:

350 I. No change in all parameters: All the parameters of the distribution are the same before and 351 after the shift. This allows to obtain samples under the null hypothesis (no shift) and therefore, 352 for each record length $n$, we calculate the probability of type one error $(\alpha)$;

353 II. Change in location parameters: The distribution before the shift $\left(G_{l}\right)$ is the same as after the 354 shift $\left(G_{2}\right)$, except for the location parameters $\beta$ in the marginal. We consider 3 cases:

355 a. Change only in location of $Q: \delta_{Q}=10,20,40$ and $70 \%$;

356 b. Change only in location of $V: \delta_{V}=10,20,40$ and $70 \%$;

c. Change in the location of $Q$ and $V$ simultaneously: $\left(\delta_{Q}, \delta_{V}\right)=(10,10),(20,20),(20,-20)$, $(40,40)$, and $(70,70) \%$.

359 For the evaluation of $\mathrm{p}$-values, based on the permutation and the bootstrap methods, we use $n_{p}=$

360500 permutations or bootstrap samples. This value of $n_{p}$ is proposed by Li and Liu [2004] for the

361 M- and T-tests and is superior to the value 200 proposed by Baringhaus and Franz [2004] for the 362 C-test. 
363 In the second step of the simulation study, we evaluate the performance of each test on the basis of

364 the estimate $\hat{\alpha}$ of the type one error $\alpha$ and the power of the considered tests. In the present study,

365 we fix $\alpha=5 \%$. Consequently, we reject $H_{0}$ if the p-value is less than $5 \%$. We consider a number of

366 replications $N=3000$ which higher than the number of replications used by Li and Liu [2004],

367 Wilcox [2005] and Zhang et al. [2009].

368 Since the peak and the volume have very different scales, we also considered standardizing the 369 generated samples (with the known standard deviation and its empirical estimate of the whole

370 sample before and after the shift). Note that the standard deviation of a Gumbel distribution can be

371 obtained directly from its scale parameter $\sigma$ as $\pi \sigma / \sqrt{6}$.

\section{4.3. Simulation results}

373 In order to avoid repetition and for notation simplicity, the depth function will only be written in

374 the test index when it is needed. For example, $\mathrm{M}_{\mathrm{TD}}$-test is the M-test with TD depth function.

$375 \quad$ I. $\quad$ Type one error estimation

376 The estimates $\hat{\alpha}$ of $\alpha$ for the considered tests are presented in Table 2 (with and without

377 standardization). First, we observe that the results are almost the same with and without 378 standardization for all situations and tests. Since the critical level is fixed at $\alpha=5 \%$, a performing

379 test should have $\hat{\alpha}$ as close as possible to 5\%. From Table 2, we see that $\hat{\alpha}$ generally approaches

$3805 \%$ when $n$ increases. Values of $\hat{\alpha}$ for the M-test are close to 5\% except for $\mathrm{M}_{\mathrm{TD}}$ and $\mathrm{M}_{\mathrm{SD}}$ in the 381 case $(n, s)=(30,10)$. The T- and C-tests have $\hat{\alpha}$ around 5\% whatever the sample size. The W-test 382 underestimates $\alpha$ while the QIB-, QIA- and Z-tests overestimate it. However, the QIB SD- $^{-}$QIATD383 and $\mathrm{Z}_{\mathrm{TD}}$ - tests have $\hat{\alpha}$ higher than $20 \%$ when $(n, s)=(30,10)$ which means that they reject $H_{0}$ more 384 frequently when it is true. 


\section{Power evaluation}

387 Table 3 summarises the simulation results for shift detection tests for several shift amplitudes in $Q$,

$388 V$ and $(Q, V)$. In general, these results show good behaviour for the tests in terms of power. The 389 power increases with the shift amplitude $\delta$ and with the sample size $n$. In the present paper, a test 390 power is considered high when it exceeds $95 \%$.

391 For $n=30$, Table 3 (part a) shows that high powers are generally recorded for large shift amplitudes

392 i.e. $\left(\delta_{Q}, \delta_{V}\right)=(70,0)$ or $\left(\delta_{Q}, \delta_{V}\right)=(70,70)$. For the M- and T-tests, best powers are recorded 393 with the MD depth function. The TD depth function gives best powers for the W-, QIA- and Z394 tests while for the QIB-test, the best power is reached with the SD depth function. However, as 395 seen before, the $\mathrm{QIB}_{\mathrm{SD}^{-}}$, $\mathrm{QIA}_{\mathrm{TD}^{-}}$and $\mathrm{Z}_{\mathrm{TD}^{-}}$tests are problematic when estimating $\alpha$. Note that the 396 depth function that provides the best test power is not necessarily the one with which the test was 397 originally defined, e.g. M- and T-tests. For the C-test, the power depends on the variable in which 398 the shift has occurred. Indeed, a shift only in $Q$ leads to low power for the C-test, while the opposite 399 is true when the shift is either in $V$ or in $(Q, V)$. This is due to the difference in the first term in (7) 400 which can be affected by the scale of the series. In the case of floods, $Q$ and $V$ series have very 401 different scales. Consequently, a change in $Q$ does not have a great effect on the test statistic while 402 the opposite is true for $V$ (and hence for $(\mathrm{Q}, \mathrm{V})$ ). We can conclude that the C-test is more sensitive 403 to a change in $V$ than a change in $Q$. This result was not shown in previous studies since the 404 simulations were based on variables of the same nature and scale. This can be explained by the fact 405 that the statistic $\mathrm{C}$ is based on the Euclidian distance which is not affine invariant whereas the 406 depth-based tests are not affected by the scale since depth functions are usually affine invariant 407 [Zuo and Serfling, 2000]. 
408 For $n=50$, from Table 3 (part b), we can see that high powers are obtained starting form $\left(\delta_{Q}, \delta_{V}\right)$

$409=(0,40)$. For each test, the depth functions that lead to the best power when $n=30$ are generally

410 the same when $n=50$. The powers when $n=50$ are generally higher than the power corresponding

411 to $n=30$ with a few exceptions: for QIB-, QIA-, and Z-tests with $\left(\delta_{Q}, \delta_{V}\right)=(0,10),(10,0),(10,10)$,

$412(0,20),(20,0)$ or $(20,20)$.

413 Table 3 (part c) summarizes the simulation results of the presented tests when $n=80$. Results show

414 that high powers are observed starting from $\left(\delta_{Q}, \delta_{V}\right)=(20,-20)$ for the M-, T- and $\mathrm{W}_{\mathrm{TD}}$-tests. For

415 the M-test, results are similar for the three considered depth functions for each shift amplitude

416 whereas for the other tests, depth functions leading to the highest powers for $n=80$ are also the

417 same as for $n=30$ or 50 . Generally, the performances of the tests increase when the shifts of $V$ and

$418 Q$ have different signs. For instance, the powers for $\left(\delta_{Q}, \delta_{V}\right)=(20,-20)$ are higher than those

419 corresponding to $\left(\delta_{Q}, \delta_{V}\right)=(20,20)$ for all tests. Note that the C-test power increases with $n$ except

420 when the shift is located only in $Q$.

421 From these results one can conclude that, generally, best results are obtained by the M-, T- and W-

422 tests (with power higher or equal to that of the rest of the tests). For low sample sizes, high powers

423 are observed for large shift amplitudes (70\%), while for large sample sizes, high powers are

424 observed starting from $\left(\delta_{Q}, \delta_{V}\right)=(20,-20) \%$. For low shift amplitudes $(10 \%)$, low powers are

425 recorded for all the considered tests. Figure 2 illustrates the applicability (where power is

426 reasonable or high) of considered tests for the combinations of the studied sample sizes and shift 427 amplitudes.

428 As shown in Table 3, the powers of the tests, in particular the C-test, are affected by the different

429 scales in the variables $\mathrm{V}$ and Q. Table 4 presents results corresponding to the case when the 
430 generated series are standardized using the corresponding estimated standard deviation. We 431 observe that the standardized C-test provides better results especially when the change is

432 symmetrical in V or in Q, such as the case $\left(\delta_{Q}, \delta_{V}\right)=(0,20)$ or $(20,0) \%$. However, it is still affected

433 in the sense that the power is not the same when the variables are affected symmetrically. The other 434 tests remain almost the same after standardization even though the power is reduced for some tests 435 (e.g. QIB_SD, QIA, $n=50)$.

436 In Table 5, we consider standardizing with the estimated or known standard deviation. We observe 437 from Table 5 that the power is close to being symmetric regarding the change in $\mathrm{V}$ or $\mathrm{Q}$ when the 438 standard deviation is estimated, and the power becomes almost symmetric when the standard 439 deviation is known. The improvement is increasing with the sample size where, for instance, the 440 power is almost identical when a change affects either $\mathrm{V}$ or $\mathrm{Q}$ with the same shift magnitude. Note 441 that by construction, the depth-based tests should not be affected by the scale since the depth 442 functions are affine-invariant (see Li and Liu, 2004).

443 Table 6 presents evaluations of the power of the previous tests (with standardized samples) with 444 different possibilities of the location of the shift through different values of s. We observe that for 445 a given $n$, the power generally increases with $s$, with some exceptions such as for QIA and QIB for 446 which the power decreases with $s$. We observe also that small values of $s$ (mainly s $=5$ in the 447 present study) affect the depth computations of some tests like the M and QIB tests which presented 448 unexpected behaviors (always 0\% for M or 100\% for QIB).

449 Variations of the type one error $(\alpha)$ estimations and the power with respect to the dependence level 450 are presented in Table 7. Regarding $\alpha$ estimation, for a given test, the estimation is practically 451 unaffected for all three dependence levels. Regarding the power, in general for all depth-based 
tests, the power is increasing with some exceptions related to the values of $\delta_{\mathrm{Q}}$ and $\delta_{\mathrm{V}}$, such as $(0,10)$

453 and $(10,10)$. The C-test seems to be almost unaffected by the dependence level.

454 During the simulation, a problem related to the set $\Omega$ occurred with the T-test. Indeed, the set $\Omega$ 455 given in (9) can be empty. It was observed that $\Omega$ is rarely empty in general with the SD and MD 456 depths, but it is often empty with the TD depth. This issue was not mentioned or considered in $L i$ 457 and Liu [2004]. These cases are excluded from the present computations.

458 From the present simulation study, the following general observations can be made (also illustrated 459 in Figure 2):

$460 \quad$ - The C-test is more sensitive to a change in $V$ than a change in $Q$;

$461 \quad$ - For a small sample size $(n=30)$, high power is observed only for high shift amplitudes;

$462 \quad$ - For a large sample size $(n=80)$, best powers are observed for the M-, T- and W-tests;

463 - The QIB-, QIA- and Z-tests can be problematic especially for low shift amplitudes;

$464 \quad$ - For type one error estimation, $\mathrm{QIB}_{\mathrm{SD}^{-}}$, the QIA- and $\mathrm{Z}_{\mathrm{TD}}$-tests are problematic, especially 465 when $n=30$. Good performances are observed for the M-, T-, W- and C-tests with all depth 466 functions;

$467 \quad-\quad$ For low shift amplitudes $\left(\delta_{Q}, \delta_{V}\right)=(0,10),(10,0)$ or $(10,10)$, powers are low. This means 468 that a $10 \%$ change in one or both location parameters is not detected by the considered tests;

$469 \quad$ - The C-test is severely affected by the scale and samples should be standardized to reduce 470 this effect. However, the depth-based tests are less affected by the variable scale;

471 - Generally, the power increases with the location shift $s$. However, some tests provided 472 inconsistent results when $s$ is very close to the beginning (or the end) of the series;

473 - Generally the power of the depth-based tests increases with the dependence level whereas 474 the C-test is almost unaffected by this factor. 
476 In this section, the previously considered tests are applied to the data series of three stations

477 (Moisie, Magpie and Romaine) with natural flow regimes. Moisie and Romaine are among a 478 number of stations selected in Canada to be part of the Reference Hydrometric Basin Network 479 (RHBN) used for the study of the impacts of climate change on hydrologic regimes in the country 480 [Ouarda et al. 1999]. The three considered stations are located in the Cote Nord Region of the 481 province of Quebec, Canada. The Moisie station (reference number 072301) is located on Moisie 482 River at $1.5 \mathrm{~km}$ upstream of the Québec North Shore Labrador Railway (QNSLR) bridge with a 483 drainage basin area of $19012 \mathrm{~km}^{2}$. Data series are available from 1968 to 1998. The Magpie station 484 (reference number 073503) is located at the outlet of Magpie Lake. Its drainage basin has an area 485 of $7201 \mathrm{~km}^{2}$ and observations are available from 1979 to 2004 . The Romaine station (reference 486 number 073801) is located at $16.4 \mathrm{~km}$ from the Chemin-de-fer bridge on Romaine River, with a 487 drainage basin area of $12922 \mathrm{~km}^{2}$ and available data from 1961 to 2006. Figure 3 and Table 7 488 present respectively the geographical location and general information about the considered 489 stations.

490 Spring flood characteristics $Q$ and $V$ are extracted from daily streamflow series for each station. 491 The peak $Q$ is defined as the maximum annual of daily streamflow series whereas the volume $\mathrm{V}$ is 492 the cumulative streamflow over the flood event, see e.g. Aissia et al. [2012] for formal definitions 493 of flood variables. Note that the variables $Q$ and $V$ correspond to the same flood event each year.

494 In particular, they correspond to the annual spring flood event which is generally the important 495 flood event in the year and is caused mainly by snow melting [Aissia et al., 2012].

496 Figure 4 shows the time series of $Q$ and $V$ for the three stations. Since these stations are 497 geographically close to each other (Figure 3), it is expected that any eventual shift would be 
498 observed in all three stations. From Figure 4 we can see that a shift can be located in $Q$ and $V$

499 around 1984 for all three stations. Therefore, the previously presented tests (with and without

500 standardizing the samples) are applied for each station in 1984. Statistics and p-values of the

501 considered tests are summarized in Table 8. Note that, instead of the p-value, for the W-test the

502 conclusion is presented as: 1 if there is a shift, 0 if not, since this test is based on critical thresholds

503 [Wilcox, 2005].

504 First, we observe that the standardization does not affect the values of the test statistics of the depth-

505 based tests whereas the C-test statistics are completely different. However, the p-values are almost

506 the same and the standardization generally does not change the conclusions. Results show that all

507 considered tests are in agreement with the existence of a shift in the Moisie station data. For

508 instance, the p-values of the T-, QIB-, QIA-, Z- and C-tests are less than 1\%. For Magpie station,

509 the M-test is the only test which does not detect the presence of a shift for all depth functions

510 whereas the T-test indicates a shift with all depth functions. This can be explained by the fact that

511 for small sample sizes (Table 3a) the power of the M-test is lower than the power of the T-test.

512 Considering Romaine station, only the $\mathrm{T}_{\mathrm{SD}^{-}}, \mathrm{QIB}_{\mathrm{TD}^{-}}, \mathrm{QIB}_{\mathrm{MD}^{-}}$and $\mathrm{Z}_{\mathrm{TD}^{-}}$tests cannot confirm the

513 existence of a shift in the year 1984.

514 From the results of the three stations, one can conclude that, the year 1984 is detected as a shift for

515 the Moisie station by all tests (and depth functions) and for Romaine station by all tests (not all

516 depth functions). However, for the Magpie station, 3 out of 6 tests detect the shift. Indeed, from

517 Figure 4b one can see that a shift in 1984 is not very clear in Magpie station and the short sample

518 data before the shift can have an impact on the power of considered tests. Since these stations are

519 geographically close (Figure 3), one can say that 1984 represents probably a shift for all these

520 stations. 


\section{Conclusions}

522 The aim of this paper is to study shift detection in the multivariate hydrological setting by

523 comparing the power of several tests and by adapting these tests for hydrological practice. Shift

524 detection is required to insure the validity of HFA assumptions (homogeneity and stationarity) and

525 has hence a strong impact on the selection of the appropriate multivariate distribution. All

526 considered tests are based on data depth, except for the C-test, which is considered for comparison

527 purposes. An overall simulation study that considers all the considered tests and which takes into

528 account the hydrological context, is performed to evaluate and compare the power of the considered

529 tests to detect shifts in the location parameter of $Q, V$ and $(Q, V)$. These tests are also applied to a

530 real-world flood case study consisting of three stations from the province of Québec, Canada.

531 In general, the powers of these tests increase with the shift amplitude and with the sample size.

532 However, the QIA-, QIB- and Z-tests may be problematic for small sample sizes and they

533 overestimate the type one error $\alpha$. The scale of the tested variables has an effect on the performance

534 of the considered tests. Especially, the C-test is severely affected and requires a standardizing of

535 the samples. In general, the tests are more powerful when the shift occurs far from the end or the

536 beginning of the series. For low shift amplitudes, the considered tests do not perform well for all

537 sample sizes. On the basis of the above comparison, and considering the nature of hydrological

538 data, it can be recommended to use the M-, T- and W-tests. More precisely, for small sample sizes,

539 the MD depth function is preferred for the M- and T-tests while the TD depth function is preferred

540 for the W-test whereas TD and SD are not recommended when testing a shift far from the middle

541 section of the series.

542 The application of the considered tests to observed hydrological data shows their ability to detect

543 multivariate shifts. It is also observed that the performance of the tests is affected by the length of 
544 the sub-series before or after the shift. The current literature review and hydrologic simulations and

545 application focused on the bivariate cases. It is recommended to examine the performance of these

546 tests for higher dimensions in future research efforts.

\section{ACKNOWLEDGEMENTS}

548 The authors are grateful to the Editor, the Associate Editor and the reviewers for their comments

549 and suggestions which helped improve the quality of the paper. The authors thank the Natural

550 Sciences and Engineering Research Council of Canada (NSERC) for the financial support and

551 Marjolaine Dubé for her assistance.

\section{References}

553 Aissia, M. A. B., F. Chebana, T. B. M. J. Ouarda, L. Roy, G. Desrochers, I. Chartier, and É. 554 Robichaud (2012), Multivariate analysis of flood characteristics in a climate change context of the 555 watershed of the Baskatong reservoir, Province of Québec, Canada, Hydrological Processes, 26(1), 556 130-142.

557 Baringhaus, L., and C. Franz (2004), On a new multivariate two-sample test, Journal of 558 Multivariate Analysis, 88(1), 190-206.

559 Beaulieu, C., T. B. M. J. Ouarda, and O. Seidou (2007), A review of homogenization techniques 560 for climate data and their applicability to precipitation series, Hydrological Sciences Journal, $561 \quad 52(1), 18-37$.

562 Beaulieu, C., O. Seidou, T. B. M. J. Ouarda, X. Zhang, G. Boulet, and A. Yagouti (2008), 563 Intercomparison of homogenization techniques for precipitation data, Water Resources Research, 564 44(2), W02425.

565 Beaulieu, C., Seidou, O., Ouarda, T.B.M.J., and X. Zhang (2009). Intercomparison of 566 homogenization techniques for precipitation data continued: Comparison of two recent Bayesian change point models, Water Resources Research, 45, W08410, doi:10.1029/2008WR007501.

Beaulieu, C., Ouarda, T.B.M.J., and O. Seidou. (2010). A Bayesian Normal Homogeneity Test for the detection of artificial discontinuities in climatic series, International Journal of Climatology, DOI: 10.1002/joc.2056.

Bobée, B., and F. Ashkar (1991), The gamma family and derived distributions applied in hydrology, Water Resources Publication. Littleton, Colorado, USA.

573 Bowman, A. W., A. Pope, and B. Ismail (2006), Detecting discontinuities in nonparametric regression curves and surfaces, Statistics and Computing, 16(4), 377-390.

Burn, D. H., and M. A. Hag Elnur (2002), Detection of hydrologic trends and variability, Journal of Hydrology, 255, 107-122.

Chebana, F. (2013), Multivariate Analysis of Hydrological Variables, in Encyclopedia of Environmetrics, edited, John Wiley \& Sons, Ltd.

579 Chebana, F., and T. B. M. J. Ouarda (2007), Multivariate L-moment homogeneity test, Water

580 Resources Research, 43(8). 
Chebana, F., and T. B. M. J. Ouarda (2008), Depth and homogeneity in regional flood frequency analysis, Water Resources Research, 44(11).

Chebana, F., and T. B. M. J. Ouarda (2009), Index flood-based multivariate regional frequency analysis, Water Resources Research, 45(10), W10435.

Chebana, F., and T. B. M. J. Ouarda (2011), Multivariate quantiles in hydrological frequency analysis, Environmetrics, 22(1), 63-78.

Chebana, F., T. B. M. J. Ouarda, and T. C. Duong (2013), Testing for multivariate trends in hydrologic frequency analysis, Journal of Hydrology, 486(0), 519-530.

Chebana, F., T. B. M. J. Ouarda, P. Bruneau, M. Barbet, S. El Adlouni, and M. Latraverse (2009), Multivariate homogeneity testing in a northern case study in the province of Quebec, Canada, Hydrological Processes, 23(12), 1690-1700.

Chen, S., Li, Y., Kim, J. and Kim, S. W. (2016), Bayesian change point analysis for extreme daily precipitation. Int. J. Climatol.. doi:10.1002/joc.4904

Cramér, H. (1928), On the composition of elementary errorsé: II, Statistical applications, Skandinavisk Aktuarietidskrift, 11, 141-180.

Deng, J. L. (1989), Introduction to Grey System Theory, J. Grey Syst., 1(1), 1-24.

Dovoedo, Y.H. and Chakraborti, S. (2015), Power of depth-based nonparametric tests for multivariate locations, Journal of Statistical Computation and Simulation, 85:10, 1987-2006

Easterling, D. R., and T. C. Peterson (1995), A new method for detecting undocumented discontinuities in climatological time series, International Journal of Climatology, 15(4), 369-377. Efron, B., and R. J. Tibshirani (1994), An Introduction to the Bootstrap, Taylor \& Francis.

El Adlouni, S., Chebana, F., and Bobée, B. (2010), Generalized Extreme Value versus Halphen System: Exploratory Study. J. Hydrol. Eng., 10.1061/(ASCE)HE.1943-5584.0000152, 79-89.

Ehsanzadeh, E., Ouarda, T. B. M. J. and Saley, H. M. (2011), A simultaneous analysis of gradual and abrupt changes in Canadian low streamflows. Hydrol. Process., 25: 727-739. doi:10.1002/hyp.7861

Genest, C., and L.-P. Rivest (1993), Statistical Inference Procedures for Bivariate Archimedean Copulas, Journal of the American Statistical Association, 88(423), 1034-1043.

Good, P. (2005), Permutation, Parametric and Bootstrap Tests of Hypotheses, 315 pp., Springer New York.

Gumbel, E. J., and C. K. Mustafi (1967), Some Analytical Properties of Bivariate Extremal Distributions, Journal of the American Statistical Association, 62(318), 569-588.

Hobæk Haff, I., K. Aas, and A. Frigessi (2010), On the simplified pair-copula construction Simply useful or too simplistic?, Journal of Multivariate Analysis, 101(5), 1296-1310.

Hotelling, H. (1947), Multivariate quality control: Illustrated by the air testing of sample bomb sight., in In Selected Techniques of Statistical Analysis for Scientific and Industrial Research and Production and Management Engineering, edited by McGraw-Hil, pp. 111-184, New York.

Jandhyala, V., P. Liu, S. Fotopoulos, and I. MacNeill, (2014) Change-Point Analysis of Polar Zone Radiosonde Temperature Data. J. Appl. Meteor. Climatol., 53, 694-714,doi: 10.1175/JAMC-D13-084.1.

Kao, S.-C., and R. S. Govindaraju (2007), A bivariate frequency analysis of extreme rainfall with implications for design, J. Geophys. Res., 112(D13), D13119.

Lee, T.-S., Ouarda, T.B.M.J., Chebana, F., and D. Park (2014), Evaluation of a Depth-Based Multivariate -Nearest Neighbor Resampling Method with Stormwater Quality Data, Mathematical Problems in Engineering, 2014 (404198), doi:10.1155/2014/404198.

Li, J., and R. Y. Liu (2004), New Nonparametric Tests of Multivariate Locations and Scales Using Data Depth, Statistical Science, 19(4), 686-696. 
Lin, L., and M. Chen (2006), Robust estimating equation based on statistical depth, Statistical Papers, 47(2), 263-278.

630 Liu, R. Y. (1990), On a Notion of Data Depth Based on Random Simplices, The Annals of 631 Statistics, 18(1), 405-414.

632 Liu, R. Y., and K. Singh (1993), A Quality Index Based on Data Depth and Multivariate Rank Tests, Journal of the American Statistical Association, 88(421), 252-260. Liu, R. Y., and K. Singh (2006), Rank tests for multivariate scale difference based on data depth, in Data Depth: robust multivariate analysis, computational geometry, and applications, edited by R. Y. S. Liu, K. and Souvaine, D.L., pp. 17-35, Àmerican Mathematical Society.

Lund, R., and J. Reeves (2002), Detection of Undocumented Changepoints: A Revision of the TwoPhase Regression Model, Journal of Climate, 15(17), 2547-2554. Association, 99(468), 949-966. Moore, R. E. (1979), Methods and Applications of Interval Analysis, SIAM, Philadelphia, USA. Naizghi, M. S., and T. B. M. J. Ouarda (2016). Teleconnections and analysis of long-term wind speed variability in the UAE, International Journal of Climatology, DOI: 10.1002/joc.4700.

Ouarda, T. B. M. J. and S. El-Adlouni (2011). Bayesian nonstationary frequency analysis of hydrological variables. Journal of the American Water Resources Association (JAWRA), 1-10, 47(3): 496-505. DOI: 10.1111/j.1752-1688.

Ouarda, T., M. Haché, P. Bruneau, and B. Bobée (2000), Regional Flood Peak and Volume Estimation in Northern Canadian Basin, Journal of Cold Regions Engineering, 14(4), 176-191.

Ouarda, T.B.M.J., Rasmussen, P.F., Cantin, J.F., Bobée, B., Laurence, R., Hoang, V.D. and G. Barbé (1999). Identification of a hydrometric data network for the study of climate change over the province of Quebec. Revue des Sciences de l'eau, 12(2): 425-448.

Ouarda, T.B.M.J., Charron, C., Niranjan Kumar, K., Marpu, P., Ghedira, H., Molini, A.L., Khayal (2014). Evolution of rainfall regime in the UAE, Journal of Hydrology, 514 (June): 258-270, DOI:10.1016/j.jhydrol.2014.04.032.

Peterson, T. C., et al. (1998), Homogeneity adjustments of in situ atmospheric climate data: A review, International Journal of Climatology, 18(13), 1493-1517.

Rao, A. R., and K. H. Hamed (2000), Flood Frequency Analysis, CRC Press, Boca Raton.

Sagarin, R., and F. Micheli (2001), Climate change in nontraditional data sets, Science, 294(5543), 811.

Seidou, O., and T.B.M.J., Ouarda (2007). Recursion-based multiple changepoint detection in multivariate linear regression and application to river streamflows, Water Resources Research. 43, W07404, doi:10.1029/2006WR005021, 1-18.

Seidou, O., J. J. Asselin, and T. B. M. J. Ouarda (2007), Bayesian multivariate linear regression with application to change point models in hydrometeorological variables, Water Resources Research, 43(8),.

Shiau, J. T. (2003), Return period of bivariate distributed extreme hydrological events, Stochastic Environmental Research and Risk Assessment, 17(1-2), 42-57.

Singh, S. K., and A. Bárdossy (2012), Calibration of hydrological models on hydrologically unusual events, Advances in Water Resources, 38(0), 81-91.

Sklar, A. (1959), Fonctions de répartition à $n$ dimensions et leurs marges.

Snedecor, G. W., and W. G. Cochran (1967), Statistical Methods, Iowa State University Press.

Solow, A. R. (1987), Testing for Climate Change: An Application of the Two-Phase Regression Model, Journal of Climate and Applied Meteorology, 26(10), 1401-1405. 
Song, S., and V. P. Singh (2009), Meta-elliptical copulas for drought frequency analysis of periodic hydrologic data, Stochastic Environmental Research and Risk Assessment, 1-20. Tukey, J. W. (1975), Mathematics and the picturing of data, paper presented at International Congress of Mathematicians, Canad. Math. Congress,, Vancouver, B. C., 1974. Vandenberghe, S., N. E. C. Verhoest, and B. De Baets (2010), Fitting bivariate copulas to the dependence structure between storm characteristics: A detailed analysis based on 105 year 10 min rainfall, Water Resour. Res., 46(1), W01512.

Vincent, L. A. (1998), A Technique for the Identification of Inhomogeneities in Canadian Temperature Series, Journal of Climate, 11(5), 1094-1104.

Wang, X. L. (2003), Comments on "Detection of Undocumented Changepoints: A Revision of the Two-Phase Regression Model”, Journal of Climate, 16(20), 3383-3385.

Wazneh, H., Chebana, F., Ouarda, T.B.M.J. (2015), Delineation of homogeneous regions for regional frequency analysis using statistical depth function, Journal of Hydrology, Vol. 521: 232244.

Wazneh H., Chebana F. and Ouarda T.B.M.J. (2013), Optimal depth-based regional frequency analysis. Hydrol. Earth Syst. Sci., 17 : 2281-2296. DOI : 10.5194/hess-17-2281-2013

690 Wilcox, R. R. (2005), Depth and a multivariate generalization of the Wilcoxon-Mann-Whitney test, 691 American Journal of Mathematical and Management Sciences, 25(3-4), 343-363.

692 Wong, H., B. Q. Hu, W. C. Ip, and J. Xia (2006), Change-point analysis of hydrological time series using grey relational method, Journal of Hydrology, 324(1-4), 323-338.

694 Ye, N., S. M. Emran, Q. Chen, and S. Vilbert (2002), Multivariate statistical analysis of audit trails

695 for host-based intrusion detection, IEEE Transactions on Computers, 51(7), 810-820.

696 Yue, S. (2001), A bivariate gamma distribution for use in multivariate flood frequency analysis, Hydrological Processes, 15(6), 1033-1045.

Yue, S., T. B. M. J. Ouarda, B. Bobée, P. Legendre, and P. Bruneau (1999), The Gumbel mixed model for flood frequency analysis, Journal of Hydrology, 226(1-2), 88-100.

Zhang, C., Z. Lin, and J. Wu (2009), Nonparametric tests for the general multivariate multi-sample problem, Journal of Nonparametric Statistics, 21(7), 877-888.

Zuo, Y., and R. Serfling (2000), General notions of statistical depth function, Ann. Statistics, 28, 461-482.

706 Zuo, Y., and X. He (2006), On the limiting distributions of multivariate depth-based rank sum statistics and related tests, Annals of Statistics, 34(6), 2879-2896. 


\section{Tables}

Table 1: Summary of the presented tests

\begin{tabular}{|c|c|c|c|c|c|c|}
\hline & \multirow{2}{*}{ Reference } & \multirow{2}{*}{ Designed to detect } & \multirow{2}{*}{ p-value evaluation } & \multirow{2}{*}{ Used depth functions } & \multicolumn{2}{|c|}{ Comparison from the literature } \\
\hline & & & & & For normal samples & For non-normal samples \\
\hline $\begin{array}{l}\text { C-test } \\
\text { Eq. (7) }\end{array}$ & $\begin{array}{l}\text { Baringhaus } \\
\text { and Franz } \\
(2004)\end{array}$ & $\begin{array}{l}\text { Location and/or } \\
\text { scale shift }\end{array}$ & Bootstrap & NA & \multicolumn{2}{|c|}{ The C-test performs almost as well as Hotelling test } \\
\hline $\begin{array}{l}\text { M-test } \\
\text { Eq. (8) }\end{array}$ & $\begin{array}{l}\mathrm{Li} \text { and Liu } \\
\quad(2004)\end{array}$ & Location shift & Permutation & $\begin{array}{l}\text { - Simplicial* } \\
\text { - Mahalanobis } \\
\text { - Half-space }\end{array}$ & \multirow{2}{*}{$\begin{array}{l}\text { The powers of M-test, } \\
\text { T-test and Hotteling } \\
\text { tests are comparable }\end{array}$} & \multirow{2}{*}{$\begin{array}{l}\text { The M-test outperformed } \\
\text { the T-test and both are } \\
\text { more powerful than the } \\
\text { Hotelling test }\end{array}$} \\
\hline $\begin{array}{l}\text { T- test } \\
\text { Eq. (11) }\end{array}$ & $\begin{array}{l}\mathrm{Li} \text { and Liu } \\
\text { (2004) }\end{array}$ & Location shift & Permutation & $\begin{array}{l}\text { - Simplicial* } \\
\text { - Mahalanobis }\end{array}$ & & \\
\hline $\begin{array}{l}\text { W-test } \\
\text { Eq. (12) }\end{array}$ & $\begin{array}{l}\text { Wilcox } \\
(2005)\end{array}$ & Location shift & $\begin{array}{l}\text { Critical thresholds } \\
\text { given in } \\
\text { Wilcox[2005] }\end{array}$ & $\begin{array}{l}\text { - Half-space } \\
\text { - Simplicial* } \\
\text { - Mahalanobis }\end{array}$ & \multicolumn{2}{|c|}{ NA } \\
\hline $\begin{array}{c}\text { Q-test } \\
\text { Eq. (13) }\end{array}$ & $\begin{array}{c}\text { Liu and } \\
\text { Singh (1993) }\end{array}$ & $\begin{array}{l}\text { Location and/or } \\
\text { positive scale shift }\end{array}$ & $\begin{array}{l}\text { Bootstrap or } \\
\text { asymptotic }\end{array}$ & $\begin{array}{l}\text { - If p-value found asymptotically: } \\
\text { Mahalanobis* or Half-space } \\
\text { - If bootstrap is the p-value } \\
\text { evaluation: Half-space or Simplicial }\end{array}$ & $\begin{array}{l}\text { The performances of } \\
\text { the Q- and Hotelling } \\
\text { tests are similar }\end{array}$ & $\begin{array}{l}\text { The Q-test outperformed } \\
\text { the Hotelling one }\end{array}$ \\
\hline $\begin{array}{c}\text { Z-test } \\
\text { Eq. (14) }\end{array}$ & $\begin{array}{l}\text { Zhang et al. } \\
\text { (2009) }\end{array}$ & $\begin{array}{l}\text { Multiple location } \\
\text { and/or scale shift }\end{array}$ & Asymptotic & $\begin{array}{l}\text { - Half-space } \\
\text { - Mahalanobis }\end{array}$ & \multicolumn{2}{|c|}{ NA } \\
\hline
\end{tabular}

*with which the test was originally developed 
Table 2 : Values of $\hat{\alpha}$ (estimate of $\alpha$ ) for the considered tests and for each sample size.

\begin{tabular}{|c|c|c|c|c|c|c|c|c|c|c|c|c|c|c|c|c|c|c|}
\hline \multirow{2}{*}{$n$} & \multirow{2}{*}{$S$} & \multicolumn{3}{|c|}{$\mathbf{M}$} & \multicolumn{3}{|c|}{$\mathbf{T}$} & \multicolumn{3}{|c|}{$\mathbf{W}$} & \multicolumn{3}{|c|}{ QIB } & \multicolumn{2}{|c|}{ QIA } & \multicolumn{2}{|c|}{$\mathbf{Z}$} & \multirow{2}{*}{$\mathbf{C}$} \\
\hline & & TD & MD & SD* & TD* & MD & SD & TD* & MD & SD & TD & MD* & SD & TD & MD* & TD & MD* & \\
\hline 30 & 10 & 1.3 & 5.2 & 0.1 & 3.9 & 5.5 & 5.0 & 2.7 & 0.2 & 1.5 & 10.1 & 6.7 & 86.5 & 46.2 & 19.3 & 22.0 & 7.6 & 5.1 \\
\hline 50 & 20 & 3.8 & 5.8 & 5.4 & 4.6 & 5.5 & 5.3 & 3.9 & 0.1 & 0.4 & 8.4 & 6.6 & 48.0 & 29.9 & 12.4 & 12.1 & 5.8 & 5.4 \\
\hline 80 & 30 & 4.1 & 5.1 & 5.0 & 5.0 & 5.2 & 5.1 & 2.6 & 0.0 & 0.2 & 6.8 & 6.0 & 27.1 & 22.8 & 9.9 & 8.2 & 4.6 & 6.0 \\
\hline \multicolumn{19}{|c|}{ Standardized versions } \\
\hline 30 & 10 & 0.5 & 4.9 & 0.1 & 4.1 & 5.9 & 5.9 & 2.9 & 0.3 & 1.5 & 10.5 & 6.8 & 86.7 & 46.5 & 19.3 & 21.6 & 7.6 & 5.3 \\
\hline 50 & 20 & 2.1 & 5.4 & 4.5 & 3.7 & 5.5 & 4.9 & 2.8 & 0.0 & 0.4 & 8.3 & 6.9 & 47.3 & 29.2 & 12.3 & 11.7 & 5.4 & 4.9 \\
\hline 80 & 30 & 4.2 & 4.9 & 4.7 & 4.9 & 5.4 & 5.4 & 2.7 & 0.0 & 0.2 & 6.6 & 5.3 & 27.9 & 23.0 & 9.9 & 8.1 & 4.3 & 4.8 \\
\hline
\end{tabular}

with $n$ : sample size, $s$ : shift, *: the depth function with which the test is originally defined. Gray color indicates that $\hat{\alpha}$ is close to $5 \%$ (between $3 \%$ and $7 \%$ ). 
Table 3 : Power comparison for the considered tests to detect shifts in $Q, V$ or $(Q, V)$.

\begin{tabular}{|c|c|c|c|c|c|c|c|c|c|c|c|c|c|c|c|c|c|c|}
\hline \multirow{2}{*}{\multicolumn{2}{|c|}{$\begin{array}{ll}\delta_{Q} & \delta_{V}\end{array}$}} & \multicolumn{3}{|c|}{$\mathbf{M}$} & \multicolumn{3}{|c|}{$\mathbf{T}$} & \multicolumn{3}{|c|}{$\mathbf{W}$} & \multicolumn{3}{|c|}{ QIB } & \multicolumn{2}{|c|}{ QIA } & \multicolumn{2}{|c|}{2} & \multirow[t]{2}{*}{ C } \\
\hline & & TD & MD & * & $\bar{D}$ & MD & * & * & MD & SD & TD & MD* & SD & TD & MD* & $\overline{T D}$ & $50 *$ & \\
\hline a) & \multicolumn{18}{|c|}{$(n, s)=(30,10)$} \\
\hline 0 & 10 & 2.5 & 0.5 & 0.1 & 7.8 & $\underline{11.6}$ & 7.8 & $\underline{7.0}$ & 0.6 & 4.0 & 10.0 & 8.0 & 84.5 & 42.4 & 19.9 & 27.1 & 9.6 & 13. \\
\hline 10 & & 0.8 & .4 & 0.1 & 5.6 & $\underline{9.0}$ & 7.7 & $\underline{5.1}$ & 0.4 & 2.7 & 9.1 & 6 & $\underline{85.4}$ & 3.1 & 9.8 & 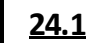 & & 4. \\
\hline 10 & 10 & 2.0 & .6 & 0 & 7.4 & $\underline{11.8}$ & 8.7 & 7.2 & 0 & 4.1 & 8.4 & 7.0 & $\underline{83.3}$ & 39.3 & 9.6 & 26.8 & 9. & 14. \\
\hline 0 & 20 & 3.0 & 7.1 & 0.3 & 23.6 & 32.6 & 23.7 & 27.1 & 5.3 & 18.6 & 16.2 & 4.9 & 89.6 & 53.0 & 32.4 & 48.7 & 20. & 40. \\
\hline 20 & & 2.1 & $\underline{17.8}$ & 0.2 & .5 & $\underline{22.2}$ & 14.8 & $\underline{16.6}$ & 2.1 & 10.4 & 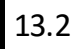 & 4 & $\underline{87.7}$ & 3.9 & 5.6 & 37.5 & 13. & 3. \\
\hline 20 & 20 & 5.7 & $\underline{26.3}$ & 0.3 & L.6 & $\underline{29.7}$ & 20.1 & $\underline{25.1}$ & 4.9 & 17.0 & 1.4 & 1.8 & $\underline{83.7}$ & 1.6 & 4.3 & 47.9 & 19 & 38. \\
\hline 20 & -20 & .1 & $\underline{54.6}$ & 0.4 & .4 & $\underline{65.0}$ & 41.5 & 0.1 & 21.6 & 47.9 & .6 & 3.2 & 95.9 & 1.1 & 1.6 & 5.7 & 46 & 40. \\
\hline 0 & 40 & 5 & 77.3 & 0.9 & 71.1 & $\underline{86.5}$ & 65.1 & 84.6 & 51.3 & 76.7 & 54.1 & 3.6 & $\underline{97.0}$ & 82.8 & 72.7 & 91.9 & 74 & 91.7 \\
\hline 40 & & 14.1 & 60.5 & 0.8 & 3.1 & $\underline{67.5}$ & 46.2 & $\underline{65.0}$ & 26.9 & 54.0 & 36.8 & 5.4 & $\underline{94.0}$ & 2.1 & 5.2 & 80.3 & 51. & 5. \\
\hline 40 & 40 & 7.1 & $\underline{74.3}$ & 0.7 & 5.7 & $\underline{80.6}$ & 63.8 & $\underline{80.6}$ & .2 & 71.1 & 9.8 & 3.3 & $\underline{94.7}$ & 9.8 & 0.2 & 1.8 & 72. & 92.3 \\
\hline 70 & 0 & 22.6 & $\underline{96.6}$ & 1.0 & 87.4 & $\underline{98.4}$ & 84.2 & 98.6 & 86.2 & 96.6 & 81.0 & 3.4 & $\underline{99.7}$ & 95.4 & 92.7 & 99.4 & 96. & 6.3 \\
\hline 70 & 70 & 23.5 & .8 & 1.4 & 86.9 & 99.2 & 90.8 & 99.2 & 93.5 & 97.5 & 83.7 & 3.6 & 99.9 & 4.7 & 4.8 & 99.9 & 99. & 9.9. \\
\hline ) & \multicolumn{18}{|c|}{$(n, s)=(50,20)$} \\
\hline 0 & 10 & .2 & $\underline{17.4}$ & 5.8 & 5.5 & $\underline{19.0}$ & 15.3 & $\underline{16.2}$ & 1.6 & 4.5 & 9.2 & 8.9 & 46.3 & 29.0 & 15.1 & 20.4 & 7.5 & 21.3 \\
\hline 10 & & 7 & $\underline{12.7}$ & L.3 & 18 & $\underline{13.4}$ & 10.4 & 10.4 & & 2.5 & 7. & 1.2 & 44.2 & 25.7 & 12. & 17.5 & & 5. \\
\hline 10 & 10 & 11.1 & 5.1 & 5.2 & 13.6 & $\underline{17.5}$ & 13.7 & 14.9 & & 3.9 & .5 & 6.4 & 39.0 & 21.3 & 1.6 & 20.8 & 8 & 22.3 \\
\hline 0 & 20 & 38.6 & 48.5 & 48.4 & 46.9 & $\underline{55.5}$ & 42.7 & $\underline{55.8}$ & 14.1 & 27.9 & 15.2 & 17.2 & $\underline{57.9}$ & 40.3 & 26.9 & $\underline{52.0}$ & 23. & 63.5 \\
\hline 20 & & 24.7 & 33.0 & 33.5 & 31.0 & 39.2 & 28.9 & $\underline{37.4}$ & & 14.4 & 11 & .3 & $\underline{51.6}$ & 3.6 & 1.1 & 7.9 & 14 & 5. \\
\hline 20 & 20 & 37.9 & 45.4 & $\underline{47.2}$ & 42.8 & $\underline{49.7}$ & 39.7 & $\underline{52.8}$ & & 25.6 & 8.4 & 1.6 & $\underline{43.5}$ & $\underline{26.0}$ & 18.7 & $\underline{55.4}$ & 24 & 65. \\
\hline 20 & -20 & 79.9 & $\underline{86.7}$ & 84.4 & 85.8 & $\underline{91.2}$ & 81.2 & $\underline{92.9}$ & 56.7 & 76.9 & 63.4 & 58.8 & $\underline{89.5}$ & 87.1 & 70.8 & $\underline{88.1}$ & 65. & 64.5 \\
\hline 0 & 40 & 95.9 & 97.5 & 97.4 & 97.0 & 98.4 & 94.8 & 99.2 & & 95.8 & 65.1 & 3.9 & $\underline{93.4}$ & 84.8 & 81.3 & $\underline{98.8}$ & 92 & 99. \\
\hline 40 & & 82.3 & $\underline{87.5}$ & 86.0 & 86.3 & $\underline{91.5}$ & 81.2 & $\underline{93.0}$ & & 78.8 & 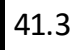 & 3.0 & $\underline{80.8}$ & 68.4 & 59.7 & $\underline{90.5}$ & 69 & 6. \\
\hline 40 & 40 & $\underline{\underline{96.8}}$ & 96.3 & $\underline{96.8}$ & 94.5 & $\underline{97.5}$ & 92.6 & $\underline{98.8}$ & .3 & 93.4 & 45.9 & 57.0 & $\underline{84.0}$ & 67.7 & 66.6 & $\underline{\underline{98.9}}$ & 90. & 99.7 \\
\hline 7 & & 99.8 & 99.9 & 99.9 & 99.3 & 100.0 & 99.5 & 0.0 & & 99.9 & 92.5 & 0.5 & $\underline{99.5}$ & 97.8 & 98.2 & 100.0 & 99. & 6.8 \\
\hline 70 & 70 & 100.0 & $\underline{\underline{100.0}}$ & 100.0 & 98.3 & $\underline{\underline{100.0}}$ & 00.0 & 100.0 & 99.8 & 99.9 & 93.5 & 3.0 & $\underline{\underline{99.8}}$ & 98.0 & 8.7 & 100.0 & 00. & 00. \\
\hline & \multicolumn{18}{|c|}{$(n, s)=(80,30)$} \\
\hline 0 & 10 & 21.3 & 22.8 & 23.5 & 2.3 & 26.3 & .9 & .2 & & 3.3 & 7. & & $\underline{25.0}$ & 22.2 & 12.7 & 17.2 & 1. & 30. \\
\hline 10 & & 12.4 & 15.3 & $\underline{16.8}$ & 15.5 & $\underline{17.9}$ & 13.4 & $\underline{13.0}$ & & 1.5 & 5. & & $\underline{23.5}$ & 19.2 & 10.0 & $\underline{11.7}$ & 5. & 4. \\
\hline 10 & 10 & 20.0 & 22.5 & $\underline{24.3}$ & 20.6 & $\underline{\underline{23.1}}$ & 19.3 & $\underline{21.2}$ & & 2.9 & 3.6 & 4.9 & $\underline{\underline{17.3}}$ & 12.9 & 8.0 & $\underline{\underline{20.2}}$ & 8. & 31.3 \\
\hline 0 & 20 & 69.0 & 70.9 & 70.4 & 69.4 & $\underline{75.5}$ & 64.0 & 76.4 & & 38.1 & 17 & 1.0 & 40.7 & \begin{tabular}{|l}
37.3 \\
\end{tabular} & 28.8 & 59.7 & 33 & 82. \\
\hline 20 & & 48.0 & 1.6 & 50.5 & 49.0 & $\underline{56.2}$ & 43.1 & $\underline{54.1}$ & & 17.5 & 11. & & $\underline{33.1}$ & 29.7 & 20.7 & $\underline{36.6}$ & 17 & 5. \\
\hline 20 & 20 & 66.7 & 64.9 & 67.4 & 65.1 & $\underline{69.0}$ & 59.1 & $\underline{73.4}$ & & 33.0 & 7.6 & 2.9 & 23.1 & 19.6 & 18.0 & 66.2 & 31. & 84. \\
\hline 20 & -20 & 97.3 & $\underline{97.8}$ & 97.0 & 97.7 & $\underline{98.6}$ & 95.6 & $\underline{\underline{99.3}}$ & 9 & 90.8 & 78.3 & 74.9 & $\underline{89.2}$ & $\underline{93.0}$ & 82.7 & $\underline{94.9}$ & 82.0 & 85.2 \\
\hline . & 40 & $\underline{99.9}$ & 99.9 & 99.8 & 99.9 & $\underline{100.0}$ & 99.6 & 100.0 & 97.4 & 99.5 & 79.0 & 87.3 & $\underline{94.7}$ & 91.1 & 90.8 & $\underline{99.8}$ & 98. & 00. \\
\hline 40 & & 98.5 & 98.2 & 98.2 & 98.3 & 99.2 & 96.2 & 99.5 & 81.2 & 92.8 & 51.7 & .5 & $\underline{78.5}$ & 73.6 & 69.6 & 79.0 & 86.4 & 5.9 \\
\hline 40 & 40 & $\underline{99.9}$ & 99.7 & 99.8 & 99.7 & 99.7 & 99.1 & 100.0 & 92.6 & 98.9 & 50.1 & 66.5 & $\underline{81.1}$ & 69.5 & $\underline{73.2}$ & 100.0 & 98.8 & 00.0 \\
\hline . & & $\underline{100.0}$ & $\underline{100.0}$ & 00.0 & 99.9 & 100. & 00.0 & 100.0 & $\underline{100}$ & $\underline{100.0}$ & 98. & & $\underline{99}$ & 99.6 & $\underline{99.7}$ & $\underline{100.0}$ & 00. & 6. \\
\hline 70 & 70 & 100.0 & & 0 & 99.7 & & & 100.0 & & 0.6 & 97.8 & & 35.5 & 39.5 & 99.9 & 100.0 & 0 . & 0. \\
\hline
\end{tabular}

with $n$ : sample size, $s$ : shift location, $\delta_{Q}$ : shift amplitude in $Q, \delta_{V}$ : shift amplitude in $V$ and $*$ : the depth function with which the test is originally defined. Gray color indicates a test power higher than $95 \%$. Numbers written in bold and underlined indicate the best power of each test for the corresponding $\left(\delta_{Q}, \delta_{V}\right)$. 
Table 4 : Power comparison for the considered tests to detect shifts in $Q, V$ or $(Q, V)$ with

standardized samples (with estimated standard deviation).

\begin{tabular}{|c|c|c|c|c|c|c|c|c|c|c|c|c|c|c|c|c|c|c|}
\hline \multirow{2}{*}{\multicolumn{2}{|c|}{$\begin{array}{ll}\delta_{\mathrm{Q}} & \delta_{\mathrm{V}}\end{array}$}} & \multicolumn{3}{|c|}{$\mathrm{M}$} & \multicolumn{3}{|c|}{$\mathrm{T}$} & \multicolumn{3}{|c|}{ W } & \multicolumn{3}{|c|}{ QIB } & \multicolumn{2}{|c|}{ QIA } & \multicolumn{2}{|c|}{ Z } & \multirow[t]{2}{*}{ C } \\
\hline & & $\mathrm{TD}$ & $\mathrm{MD}$ & SD* & TD* & $\mathrm{MD}$ & $\mathrm{SD}$ & TD* & $\mathrm{MD}$ & $\mathrm{SD}$ & $\mathrm{TD}$ & MD* & $\mathrm{SD}$ & $\mathrm{TD}$ & MD* & TD & MD* & \\
\hline \multicolumn{19}{|c|}{$(\mathrm{n}, \mathrm{s})=(30,10)$} \\
\hline$\overline{0}$ & 10 & 1.1 & $\underline{10.8}$ & 0.0 & $\overline{8.4}$ & $\underline{12.3}$ & $\overline{9.1}$ & $\underline{7.7}$ & 0.7 & 4.2 & 10.2 & 7.6 & 85.1 & 43.6 & 21.1 & 27.5 & 9.3 & 9.2 \\
\hline 10 & & 0.8 & 8.4 & 0.1 & 6.2 & $\underline{8.8}$ & 6.6 & 4.9 & 0.3 & 2.6 & 9.9 & 6.9 & $\overline{85.6}$ & $\overline{42.2}$ & 19.5 & 24.5 & 7.8 & 7.5 \\
\hline 10 & 10 & 1.0 & $1 \overline{1.3}$ & 0.1 & 7.9 & $\overline{10.7}$ & 8.5 & $\overline{6.3}$ & 0.2 & 3.5 & 7.2 & 6.3 & $\overline{83.6}$ & $\overline{36.5}$ & 17.3 & $\overline{26.3}$ & 8.8 & $1 \overline{2.6}$ \\
\hline$\overline{0}$ & 20 & 3.5 & 28.8 & 0.1 & 24.1 & 32.5 & 23.5 & 28.5 & 4.8 & 19.4 & 18.0 & 15.0 & 88.6 & 53.8 & 32.4 & 48.9 & 20.9 & 28.3 \\
\hline 20 & 0 & 2.2 & $\overline{18.4}$ & 0.1 & 14.7 & $\overline{22.8}$ & 14.9 & $\overline{16.9}$ & 2.4 & 10.6 & 12.9 & 10.6 & $\overline{87.3}$ & $\overline{49.3}$ & 26.1 & $\overline{37.0}$ & 13.5 & $\overline{17.6}$ \\
\hline 20 & 20 & 3.4 & 25.4 & 0.1 & 21.9 & 29.0 & 21.0 & 25.2 & 3.5 & 16.9 & 11.6 & 11.8 & 85.6 & 40.8 & 25.3 & 49.2 & 20.0 & 40.4 \\
\hline 20 & -20 & 6.3 & 53.8 & 0.2 & 48.0 & 64.6 & 39.9 & 60.9 & 21.6 & 48.5 & 46.5 & 38.7 & 96.2 & 84.8 & 64.0 & 78.2 & 48.1 & 52.8 \\
\hline 0 & 40 & 10.8 & 79.0 & 0.6 & 71.1 & 86.2 & 64.3 & 85.5 & 50.2 & 76.8 & 53.0 & 54.6 & $\begin{array}{l}97.3 \\
\end{array}$ & 83.6 & 73.2 & 93.4 & 75.7 & 87.0 \\
\hline 40 & 0 & 7.7 & 59.1 & 0.3 & 53.3 & 68.3 & 47.1 & 65.0 & 25.2 & 54.0 & 36.1 & 34.6 & 94.3 & 72.5 & 56.1 & 79.3 & 50.3 & 66.3 \\
\hline 40 & 40 & 9.2 & $\overline{74.3}$ & 0.6 & 66.2 & $\overline{81.1}$ & 63.6 & $\overline{81.1}$ & 42.7 & 70.8 & 38.2 & 42.2 & $\overline{94.4}$ & $\overline{68.8}$ & 60.0 & $\overline{91.7}$ & 71.2 & 93.7 \\
\hline 70 & 0 & 13.8 & 96.1 & 0.6 & 87.9 & 98.4 & 84.4 & 98.5 & 86.9 & 96.1 & 81.2 & 83.5 & 99.7 & 95.8 & 92.8 & 99.6 & 96.5 & 99.1 \\
\hline 70 & 70 & 16.2 & $\overline{99.1}$ & 1.3 & 86.0 & $\overline{99.3}$ & 91.0 & $\overline{99.3}$ & 94.1 & 98.1 & 85.2 & 89.7 & $\overline{99.9}$ & $\overline{95.3}$ & 95.2 & $\overline{99.9}$ & 99.3 & $1 \overline{00.0}$ \\
\hline \multicolumn{19}{|c|}{$(\mathrm{n}, \mathrm{s})=(50,20)$} \\
\hline 0 & 10 & 10.7 & 14.7 & 14.8 & $\overline{13.6}$ & $\overline{18.6}$ & 14.1 & 14.2 & 0.9 & 3.6 & $\overline{6.8}$ & 6.9 & 29.4 & $\underline{16.7}$ & 10.4 & 22.4 & 7.7 & $\overline{15}$ \\
\hline 10 & & 6.7 & 10.6 & $\overline{10.5}$ & 9.5 & 11.3 & 9.7 & 9.3 & 0 & 1.8 & 6.5 & 6.7 & $\overline{27.3}$ & $\overline{16.0}$ & 9.7 & $\overline{18.3}$ & 7.3 & $\overline{10.1}$ \\
\hline 10 & 10 & 9.0 & 12.4 & 12.8 & 11.4 & 13.6 & 11.9 & 11.9 & 0.7 & 2.8 & 3.6 & 4.9 & 19.9 & $\overline{10.8}$ & 7.6 & $\overline{25.3}$ & 8.2 & 19.5 \\
\hline$\overline{0}$ & 20 & 40.7 & 47.0 & 47.8 & 46.5 & 55.0 & 43.0 & $\overline{54.8}$ & 12.7 & 26.9 & 14.9 & 17.6 & 41.6 & $\overline{29.9}$ & 22.9 & $\overline{55.2}$ & 24.1 & $\overline{50.4}$ \\
\hline 20 & & 23.9 & 30.7 & $\overline{31.8}$ & 29.4 & 38.3 & 27.6 & $\overline{34.9}$ & 5.0 & 13.2 & 10.3 & 11.7 & $\overline{33.7}$ & $\overline{22.0}$ & 15.5 & $\overline{37.7}$ & 13.2 & 31.9 \\
\hline 20 & 20 & 37.5 & 42.2 & 46.0 & 42.8 & 50.0 & 38.2 & $\overline{53.6}$ & 9.6 & 25.3 & 6.8 & 11.3 & $\overline{27.8}$ & $\overline{16.9}$ & 15.2 & 63.3 & 26.3 & 67.4 \\
\hline 20 & -20 & 79.3 & 88.2 & $\overline{83.4}$ & 85.7 & 91.2 & 80.4 & $\overline{92.3}$ & 57.8 & 77.0 & 65.4 & 61.6 & $\overline{82.1}$ & $\overline{81.6}$ & 68.9 & $\overline{87.8}$ & 64.7 & $\overline{87.0}$ \\
\hline$\overline{0}$ & & 96.6 & 98.4 & 97.5 & 97.6 & 98.6 & 96.6 & $\overline{99.4}$ & 88.1 & 96.5 & 68.0 & 77.1 & 89.7 & 82.4 & 82.2 & 99.1 & 94.2 & 99 \\
\hline 40 & 0 & 83.3 & $\overline{88.4}$ & 87.9 & 87.4 & 92.2 & 84.4 & $\overline{94.3}$ & 58.7 & 80.8 & 41.7 & 49.8 & $\overline{71.8}$ & $\overline{60.4}$ & 56.8 & 92.7 & 69.1 & 93 \\
\hline 40 & 40 & 96.0 & 96.9 & 96.9 & 95.4 & 97.4 & 94.5 & 99.4 & 77.8 & 94.0 & 40.5 & 55.0 & 74.3 & 57.0 & 61.1 & 99.3 & 90.9 & 99 \\
\hline 70 & & 100.0 & 100.0 & 100.0 & 99.5 & 99.9 & $\overline{100.0}$ & 100.0 & $\begin{array}{l}99.8 \\
99.8\end{array}$ & 100.0 & 95.3 & 98.3 & 99.5 & 98.4 & 98.9 & 100.0 & 100.0 & 00.0 \\
\hline 70 & 70 & $\overline{100.0}$ & $\overline{100.0}$ & $\overline{100.0}$ & 98.8 & 100.0 & 100.0 & $\overline{\mathbf{1 0 0 . 0}}$ & 100.0 & $\overline{100.0}$ & 94.9 & 99.1 & $\overline{99.8}$ & 98.4 & $\overline{99.4}$ & 100.0 & $\overline{100.0}$ & 100.0 \\
\hline \multicolumn{8}{|l|}{ c) } & \multicolumn{11}{|c|}{$(\mathrm{n}, \mathrm{s})=(80,30)$} \\
\hline 0 & 10 & 21.3 & 23.3 & 22.7 & 21.9 & 27.1 & 19.5 & 21.8 & 12 & $\overline{3.1}$ & $\overline{6.3}$ & 8.0 & $\underline{26.7}$ & 22.8 & 12.8 & 15.0 & 7.0 & 22.9 \\
\hline 10 & 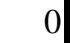 & 13.2 & $\underline{15.3}$ & 14.7 & 14.1 & 16.5 & 13.4 & $\underline{11.8}$ & 0 & 1. & 6.1 & 6.3 & $\underline{23.4}$ & 20 . & 10.4 & 3.0 & 6.9 & 14.5 \\
\hline 10 & 10 & 18.8 & $\overline{20.4}$ & 21.6 & 19.5 & 22.5 & 16.9 & $\overline{19.5}$ & 0.7 & 2.6 & 3.2 & 4.6 & $\overline{15.9}$ & $\underline{12.3}$ & 7.3 & $\underline{19.6}$ & 8.0 & 31.6 \\
\hline$\overline{0}$ & 20 & 71.1 & 73.6 & 72.1 & 71.7 & 76.5 & 66.5 & 78.9 & 21.5 & 9.0 & 17.7 & 21.5 & 42.3 & $\underline{39.0}$ & 29.7 & 61.4 & 32.4 & 76.7 \\
\hline 20 & 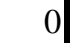 & & $\overline{51.2}$ & $\underline{51.7}$ & 50.4 & 57.5 & 45 & $\underline{56.3}$ & 7. & 16.7 & 10.9 & .6 & $\underline{32.7}$ & 29.1 & 20.3 & 38.1 & 6.2 & $\underline{55.7}$ \\
\hline 20 & 20 & 66.2 & 65.2 & $\underline{68.3}$ & 64.3 & 68.6 & 59.7 & $\overline{74.4}$ & 15.8 & 33.4 & 7.0 & 2.7 & $\underline{24.1}$ & $\overline{19.6}$ & 17.1 & $\underline{66.3}$ & 32.1 & 86.8 \\
\hline 20 & -20 & 97.2 & 97.7 & $\overline{96.6}$ & 97.5 & 98.4 & 95.1 & $\overline{98.9}$ & 78.2 & 89.8 & 78.9 & 76.2 & $\overline{90.1}$ & $\overline{92.8}$ & 83.6 & $\overline{94.3}$ & 81.9 & $\overline{98.3}$ \\
\hline 0 & 40 & $\underline{99.9}$ & 99.9 & 99.9 & 99.9 & 99.9 & 99.6 & 100.0 & 97.6 & 99.3 & 79.2 & 86.7 & 94.6 & 91.1 & 91.2 & $\underline{99.9}$ & 98.7 & 100.0 \\
\hline 40 & & $\overline{98.1}$ & $\overline{98.3}$ & $\overline{97.2}$ & 98.3 & 98.7 & 95.9 & 99.5 & 79.4 & 91.9 & 51.3 & 61.1 & $\overline{77.5}$ & $\underline{73.2}$ & 99. & 97.0 & 86.2 & 99.4 \\
\hline 40 & 40 & $\underline{99.8}$ & $\overline{99.7}$ & 99.6 & 99.5 & 99.7 & 99.0 & $\underline{\underline{100.0}}$ & 92.1 & 98.2 & 48.9 & 66.0 & $\overline{79.8}$ & $\overline{69.1}$ & 73.1 & $\overline{99.9}$ & 98.4 & $\underline{100.0}$ \\
\hline 70 & & 100.0 & 100.0 & 100.0 & $\overline{99.9}$ & 100.0 & 100.0 & 100.0 & 100.0 & 100.0 & 98.2 & 99.6 & 99.9 & $\overline{99.5}$ & $\overline{99.8}$ & 100.0 & 100.0 & 100.0 \\
\hline 70 & 70 & $\overline{\mathbf{1 0 0 . 0}}$ & $\overline{\mathbf{1 0 0 . 0}}$ & $\overline{\mathbf{1 0 0 . 0}}$ & 99.7 & 100.0 & 100.0 & $\overline{100.0}$ & $\overline{100.0}$ & 100.0 & 97.6 & 99.5 & $\overline{99.9}$ & 99.1 & $\overline{99.8}$ & $\overline{\mathbf{1 0 0 . 0}}$ & $\overline{\mathbf{1 0 0 . 0}}$ & $\overline{100.0}$ \\
\hline
\end{tabular}

with $n$ : sample size, $s$ : shift location, $\delta_{Q}$ : shift amplitude in $Q, \delta_{V}$ : shift amplitude in $V$ and $*$ : the depth function with

which the test is originally defined. Gray color indicates a test power higher than $95 \%$. Numbers written in bold and

underlined indicate the best power of each test for the corresponding $\left(\delta_{Q}, \delta_{V}\right)$. 
Table 5 : Power comparison for the considered tests to detect shifts in $Q, V$ or $(Q, V)$ with

standardized samples (with estimated or known standard deviation).

\begin{tabular}{|c|c|c|c|c|c|c|c|c|c|c|c|c|c|c|c|}
\hline \multirow{2}{*}{\multicolumn{2}{|c|}{$\delta_{\mathrm{Q}} \quad \delta_{\mathrm{V}}$}} & M & $\mathrm{T}$ & W & QIB & QIA & Z & $\mathrm{C}$ & M & $\mathrm{T}$ & W & QIB & \& & Z & $\mathrm{C}$ \\
\hline & & SD* & TD* & $\mathrm{TD}^{*}$ & MD & MD* & MD* & & $\mathrm{D} *$ & TD* & TD* & MD & MD* & $\mathrm{MD}^{*}$ & \\
\hline & & \multicolumn{7}{|c|}{ Estimated standard deviation } & \multicolumn{7}{|c|}{ Known standard deviation } \\
\hline & & \multicolumn{7}{|c|}{$(\mathbf{n}, \mathbf{s})=(\mathbf{3 0}, 10)$} & \multicolumn{7}{|c|}{$(\mathbf{n}, \mathbf{s})=(\mathbf{3 0}, 10)$} \\
\hline 0 & 10 & 0.0 & 4 & 7.7 & 7.6 & 21.1 & 9.3 & 9.2 & 0 & 6 & 5.4 & 7.2 & 19.0 & 8.3 & \\
\hline 10 & & 1 & & 4 & 6.9 & & & .5 & & & & 6.8 & & & \\
\hline 10 & 10 & 1 & 9 & 6.3 & 6.3 & 7.3 & 8.8 & 12.6 & & 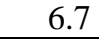 & 5.8 & 6.3 & & & 10 \\
\hline 0 & 20 & 0.1 & 24.1 & 28 & 15.0 & 32.4 & 20.9 & 28.3 & 1 & 15.6 & 17.0 & 10.6 & .2 & & 10 \\
\hline 20 & & 0.1 & .7 & 1 & 10.6 & 26.1 & 13.5 & 1 & & & .3 & 11.8 & .6 & & res \\
\hline 20 & 20 & 0.1 & 1.9 & & 8 & 25.3 & 20.0 & 40.4 & & 16 & 9.2 & 9.7 & 1.9 & & 32. \\
\hline 20 & -20 & 2 & 3.0 & 60. & & 64.0 & & 8 & & & .6 & 29.5 & .4 & & 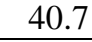 \\
\hline 0 & 40 & & .1 & & & & & & & & .0 & 4.0 & .7 & & 67. \\
\hline 40 & 0 & & & & & & & & & & & 3.3 & & & \\
\hline 40 & 40 & & & & & & & & & & & 31.3 & & & 86. \\
\hline 70 & 0 & & & & & & & & & & & 3.2 & & & \\
\hline \multirow{2}{*}{\multicolumn{2}{|c|}{70}} & & & 9.3 & 89.7 & 93 & & . & & & 8.1 & 78.8 & & & \\
\hline & & \multicolumn{7}{|c|}{$=(50,20)$} & \multicolumn{7}{|c|}{$(\mathbf{n}, \mathbf{s})=(\mathbf{5 0 , 2 0})$} \\
\hline 0 & 10 & & 3.6 & 14.2 & 6.9 & 10. & & 15.3 & & & 97 & 5.7 & 11 & & . \\
\hline 10 & & 5 & 9 & 9 & 6 & 9 & & & & & & 6. & & & 10 \\
\hline 10 & 10 & 2.8 & 11.4 & 11.9 & 4.9 & 7.6 & 8.2 & 14 & 11.9 & 1 & .0 & 5.3 & U & 6.7 & 17 \\
\hline 0 & 20 & 8 & 46.5 & & 17.6 & 22.9 & 24.1 & 5 & & & .0 & 12.4 & 2 & 14 & 36 \\
\hline 20 & & .8 & 9.4 & & & & & & & & .2 & 11.9 & 0 & & 34 \\
\hline 20 & 20 & 0 & .8 & & & & & & & & & 9.8 & .2 & & 57 \\
\hline 20 & -20 & & 85.7 & 92. & .6 & 68.9 & & 87.0 & & & 6.0 & 47.0 & 0.2 & & 75. \\
\hline 0 & 40 & & & & & & & & & & .4 & 8.0 & .0 & & 93. \\
\hline 40 & & & & & & & & & & & & 47.9 & & & 93 \\
\hline 40 & 40 & & 4 & & & 6 & 9 & . & & 80 & .1 & 8.7 & 6 & 76.3 & 9. \\
\hline 70 & & & & & & & & & & & & 7.1 & 1 & & 1 \\
\hline \multirow{2}{*}{\multicolumn{2}{|c|}{70}} & & 8 & 0.0 & 99.1 & 99.4 & & 100 & & 98.5 & 100.0 & 93.9 & 96.0 & 9 & 100 \\
\hline & & \multicolumn{7}{|c|}{$=(80,30)$} & \multicolumn{7}{|c|}{$(\mathbf{n}, \mathbf{s})=(\mathbf{8 0}, \mathbf{3 0})$} \\
\hline 0 & & & & 18 & 80 & 12. & & ?2 & & & & 6.6 & 10 & & \\
\hline 10 & & & 1 & & 6 & 10 & & & 15 & 12 & 2 & 6.6 & 1 & & 16 \\
\hline 10 & 10 & & 9.5 & & 4.6 & 7.3 & 0 & 31.6 & 17.6 & 16.1 & 5.6 & 4.7 & 8.0 & .6 & 26. \\
\hline 0 & 20 & .1 & 71.7 & 78. & 1.5 & 29.7 & 4 & 76.7 & 49 & 49 & 4.4 & 12.5 & 18.9 & 157 & 53 \\
\hline 20 & & & 5 & & & & & & & & & 13.4 & & & 52 \\
\hline 20 & 20 & & 64.3 & & & 17.1 & & 86.8 & & 52.8 & 0.3 & 10.3 & 4.9 & .3 & 76 \\
\hline 20 & -20 & 96.6 & 97.5 & 98.9 & .2 & 83.6 & 81.9 & 98.3 & 91.9 & 94.2 & 6.9 & 58.5 & 68.0 & 63.3 & 94. \\
\hline 0 & 40 & & 99.9 & 100. & & & & 100.0 & & & 9.5 & 62.8 & 0.9 & .8 & . \\
\hline 40 & 0 & 97.2 & 98.3 & & & 69 & & & & & 9.4 & 61.7 & 70.0 & & 99 \\
\hline 40 & 40 & 99.6 & 99.5 & 100.0 & 6.0 & 73.1 & 98.4 & 100.0 & 98.4 & 98.1 & 9.6 & 48.8 & 56.2 & 92.3 & 99 \\
\hline 70 & & & 99. & & & 99 & & & & & & 99.7 & 99.8 & 100.0 & 100 \\
\hline 70 & 70 & 100.0 & 99.7 & 100.0 & 99.5 & 99.8 & 100.0 & 100.0 & 100.0 & 100. & 100.0 & 98.3 & 98.8 & 100.0 & 100 \\
\hline
\end{tabular}


Table 6 : Power evaluation of the considered tests with various combinations of $\mathbf{n}$ and $\mathbf{s}$.

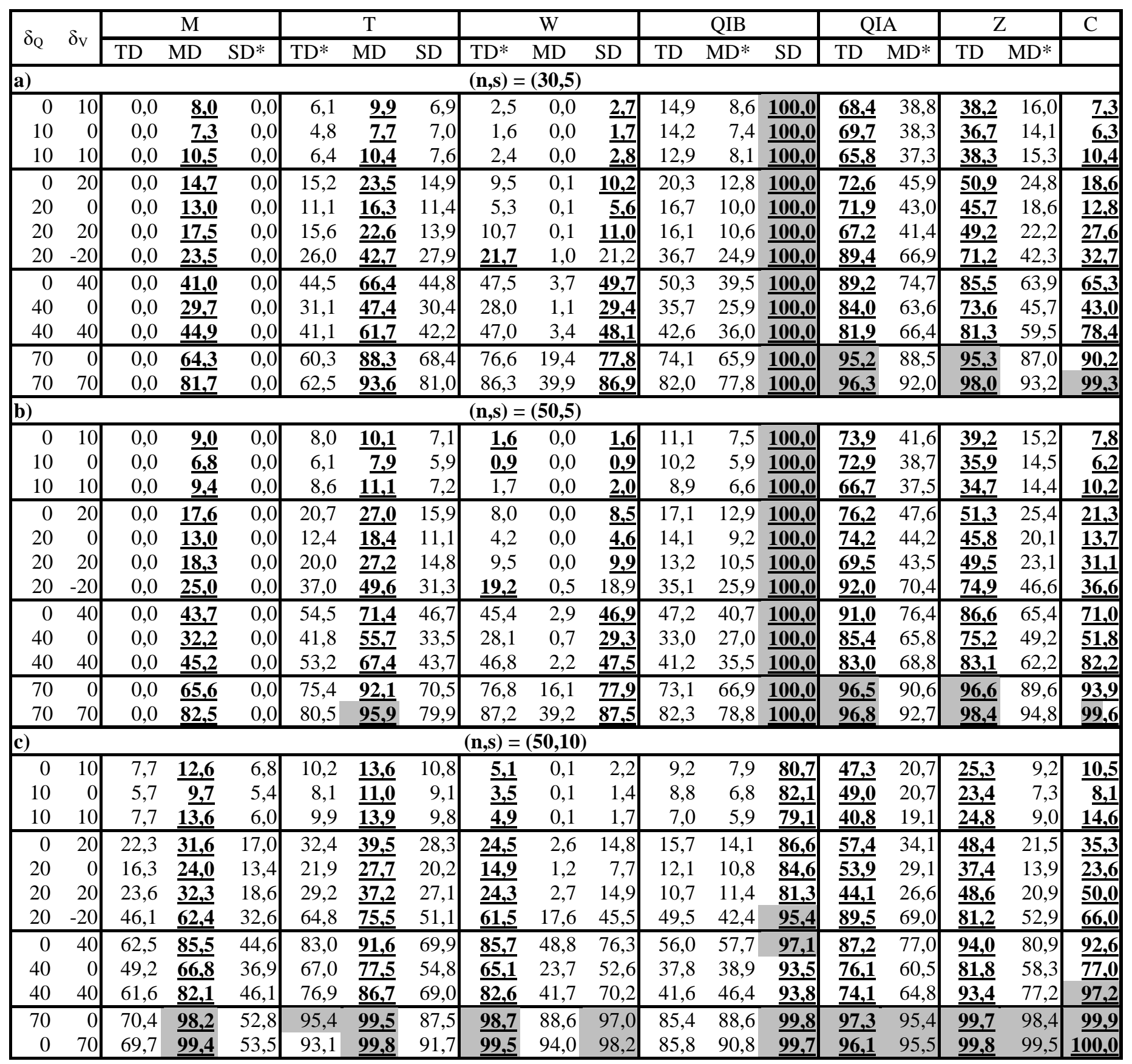




\begin{tabular}{|c|c|c|c|c|c|c|c|c|c|c|c|c|c|c|c|c|c|c|}
\hline \multirow{2}{*}{\multicolumn{2}{|c|}{$\delta_{\mathrm{Q}} \quad \delta_{\mathrm{V}}$}} & \multicolumn{3}{|c|}{$\bar{M}$} & \multicolumn{3}{|c|}{$\mathrm{T}$} & \multicolumn{3}{|c|}{$\overline{\mathrm{W}}$} & \multicolumn{3}{|c|}{ QIB } & \multicolumn{2}{|c|}{ QIA } & \multicolumn{2}{|c|}{ Z } & \multirow[t]{2}{*}{$\mathrm{C}$} \\
\hline & & TD & MD & $\mathrm{SD}^{*}$ & TD* & MD & SD & TD* & MD & $\overline{S D}$ & TD & MD* & SD & TD & MD* & TD & MD* & \\
\hline \multicolumn{8}{|l|}{ d) } & \multicolumn{11}{|c|}{$(n, s)=(80,5)$} \\
\hline$\overline{0}$ & 10 & $\overline{0,0}$ & $\underline{9,2}$ & $\overline{0,0}$ & 9,1 & $\underline{11,6}$ & $\overline{8,4}$ & $\underline{1,4}$ & $\overline{0,0}$ & $\underline{1,4}$ & $\overline{9,5}$ & $\overline{6,6}$ & 100,0 & 74,1 & 11,3 & $\overline{38,5}$ & 16,0 & 8,6 \\
\hline 10 & 0 & 0,0 & $\underline{\mathbf{8 , 1}}$ & 0,0 & 6,9 & 9,5 & 7,8 & $\underline{\underline{1,0}}$ & 0,0 & $\overline{0,9}$ & 8,3 & 6,0 & $\overline{\mathbf{1 0 0 , 0}}$ & $\overline{\mathbf{7 4 , 1}}$ & 41,0 & $\underline{37,2}$ & 15,3 & $\underline{6,6}$ \\
\hline 10 & 10 & 0,0 & $\underline{10,7}$ & 0,0 & 9,8 & 12,2 & 8,5 & 1,7 & 0,0 & $\underline{1,7}$ & 8,7 & 6,2 & 100,0 & 69,2 & 39,2 & 37,5 & 15,1 & $\underline{11,5}$ \\
\hline$\overline{0}$ & 20 & $\overline{0,0}$ & 17,3 & $\overline{0,0}$ & 22,7 & 29,7 & 19,7 & 8,1 & $\overline{0,0}$ & 8,8 & 16,7 & 13,2 & 100,0 & 77,7 & 51,4 & 53,1 & 26,6 & 23,4 \\
\hline 20 & 0 & 0,0 & $\underline{12,2}$ & 0,0 & 15,0 & $\underline{19,7}$ & 12,0 & 3,2 & 0,0 & $\underline{\mathbf{3 , 5}}$ & 11,0 & 8,9 & $\overline{100,0}$ & $\overline{\mathbf{7 6 , 0}}$ & 44,5 & 45,1 & 19,5 & 14,6 \\
\hline 20 & 20 & 0,0 & $\underline{18,4}$ & 0,0 & 20,7 & $\underline{29,0}$ & 17,4 & 7,6 & 0,0 & $\underline{7,8}$ & 11,5 & 9,8 & $\underline{100,0}$ & $\underline{\mathbf{7 0}, 9}$ & 43,8 & $\underline{49,8}$ & 22,7 & $\underline{32,5}$ \\
\hline 20 & -20 & 0,0 & $\underline{25,3}$ & 0,0 & 43,1 & $\underline{53,3}$ & 39,0 & 18,7 & 0,3 & 18,0 & 33,2 & 26,0 & 100,0 & $\mathbf{9 3 , 5}$ & 73,0 & $\underline{75,9}$ & 49,1 & 40,8 \\
\hline 0 & 40 & 0,0 & 43,8 & 0,0 & 60,8 & $\underline{74,8}$ & 54,1 & 46,7 & 2,0 & $\underline{47,3}$ & 46,0 & 40,6 & $\underline{100,0}$ & 91,5 & 77,8 & $\underline{87,0}$ & 67,6 & $\underline{75,3}$ \\
\hline 40 & 0 & 0,0 & $\underline{\mathbf{3 0 , 9}}$ & 0,0 & 43,8 & $\underline{56,1}$ & 37,9 & 25,7 & 0,4 & $\underline{26,9}$ & 30,9 & 26,0 & $\underline{100,0}$ & $\underline{86,2}$ & 64,5 & $\underline{74,2}$ & 48,6 & 51,6 \\
\hline 40 & 40 & 0,0 & $\overline{43,5}$ & 0,0 & 56,8 & $\overline{\mathbf{7 0 , 5}}$ & 48,6 & 45,7 & 1,4 & $\overline{46,2}$ & 38,2 & 34,6 & $\overline{\mathbf{1 0 0 , 0}}$ & $\overline{\mathbf{8 3 , 3}}$ & 68,3 & $\overline{\mathbf{8 3 , 2}}$ & 64,0 & $\overline{\mathbf{8 3 , 8}}$ \\
\hline 70 & 0 & 0,0 & 66,1 & 0,0 & 81,7 & $\underline{93,8}$ & 75,0 & 76,9 & 16,2 & $\underline{78,3}$ & 73,9 & 67,8 & $\underline{100,0}$ & $\underline{97,5}$ & 90,7 & $\underline{97,2}$ & 89,9 & 96,0 \\
\hline 0 & 70 & 0,0 & $\underline{\overline{81,0}}$ & 0,0 & 84,7 & $\overline{95,6}$ & 82,7 & 86,4 & 38,1 & $\underline{\overline{87,0}}$ & 81,9 & 78,8 & $\overline{100,0}$ & $\overline{96,6}$ & 93,0 & $\overline{98,7}$ & 95,3 & 99,7 \\
\hline & \multicolumn{11}{|c|}{$(\mathbf{n}, \mathbf{s})=(\mathbf{8 0 , 1 0})$} \\
\hline 0 & 10 & $\overline{9,4}$ & $\underline{13,3}$ & $\overline{10,3}$ & $\overline{12,3}$ & 15,7 & 10,7 & $\underline{4,0}$ & $\overline{0,1}$ & 1,5 & 7,8 & 7,2 & $\overline{74,9}$ & 9,4 & 22,1 & 23,9 & 8,7 & 12,1 \\
\hline 10 & 0 & 7,3 & $\overline{10,1}$ & 9,4 & 9,8 & $\overline{11,7}$ & 9,7 & $\overline{2,9}$ & 0,1 & 0,9 & 6,9 & 6,3 & $\overline{75,4}$ & $\overline{50,3}$ & 20,9 & $\overline{22,5}$ & 8,1 & 9,7 \\
\hline 10 & 10 & 9,3 & 14,1 & 10,0 & 11,8 & $\overline{15,7}$ & 10,8 & $\overline{3,9}$ & 0,2 & 1,9 & 5,4 & 5,9 & 69,6 & $\overline{43,5}$ & 19,4 & $\overline{22,3}$ & 8,3 & $1 \overline{6,5}$ \\
\hline $\mathrm{S}$ & 20 & 34,2 & 37,1 & 33,5 & 40,5 & $\overline{6,4}$ & 32,0 & 24,6 & $\overline{2}$ & 14,7 & $\overline{15,4}$ & 16,1 & 79,9 & 59,7 & 36,4 & 48,6 & 23,2 & 41,1 \\
\hline 20 & 0 & 21,7 & $\overline{25,3}$ & 21,2 & 26,2 & $\overline{32,4}$ & 22,8 & $\overline{12,9}$ & 0,8 & 6,7 & 10,7 & 10,7 & $\overline{78,4}$ & $\overline{56,3}$ & 29,7 & $\overline{\mathbf{3 6 , 0}}$ & 14,9 & $\overline{26,3}$ \\
\hline 20 & 20 & 34,8 & $\underline{36,7}$ & 33,3 & 38,6 & $\underline{44,0}$ & 31,4 & 24,7 & 2,1 & 14,2 & 9,4 & 11,2 & $\overline{72,7}$ & 4 & 28,5 & $\underline{48,3}$ & 20,6 & $\underline{\mathbf{5 6 , 8}}$ \\
\hline 20 & -20 & 64,9 & $\underline{69,8}$ & 59,8 & 74,7 & 81,9 & 56,0 & 62,4 & 15,7 & 44,9 & 49,1 & 44,3 & 93,6 & $\underline{\mathbf{9 0 , 4}}$ & 70,5 & $\underline{\mathbf{8 3}, \mathbf{0}}$ & 57,2 & 72,9 \\
\hline 0 & 40 & 80,9 & 88,2 & 76,1 & 88,7 & 93,9 & 71,6 & 85,7 & 47,5 & 75,1 & 57,0 & 59,5 & 95,5 & 88,6 & 79 & 95,1 & 82,0 & 95,8 \\
\hline 40 & 0 & 65,4 & $\overline{71,8}$ & 61,5 & 74,2 & $\underline{\mathbf{8 2 , 0}}$ & 57,6 & $\underline{65,0}$ & 20,7 & 50,1 & 35,4 & 37,4 & 91,0 & $\overline{\mathbf{7 8 , 8}}$ & 62,0 & $\underline{\mathbf{8 3 , 7}}$ & 58,6 & $\underline{82,0}$ \\
\hline 40 & 40 & 79,5 & $\underline{\mathbf{8 3 , 5}}$ & 74,9 & 82,9 & $\underline{89,1}$ & 70,7 & $\mathbf{8 1 , 9}$ & 39,3 & 69,3 & 40,5 & 46,3 & 91,0 & $\overline{76,3}$ & 65,3 & 93,7 & 78,0 & 98, \\
\hline 70 & & 87,6 & 99,1 & 83,6 & 97,2 & 99,7 & 86,5 & 98,7 & 86,2 & 95,9 & 84,2 & 87,4 & 99,4 & 97,1 & 94,5 & 99,7 & 98,4 & 99 \\
\hline 0 & 70 & 89,6 & $\overline{99,7}$ & 85,3 & 95,8 & $\overline{99,8}$ & 91,7 & $\overline{99,5}$ & 94,5 & 98,3 & 87,4 & 92,0 & $\overline{99,8}$ & $\overline{97,2}$ & 96,6 & $\overline{99,9}$ & 99,6 & $\overline{100,0}$ \\
\hline \multicolumn{8}{|l|}{ 1) } & \multicolumn{11}{|c|}{$(\mathbf{n}, \mathbf{s})=(\mathbf{8 0}, 20)$} \\
\hline 0 & 10 & 14,6 & 3,8 & $\underline{19,5}$ & 18,3 & $\underline{22,4}$ & 17,7 & $\underline{12,1}$ & $\overline{0.3}$ & 2 , & $\overline{7,}$ & 7,7 & $\underline{37,0}$ & $\underline{30,9}$ & 15,7 & $\underline{16,6}$ & 6,4 & $\underline{18,1}$ \\
\hline 10 & 0 & 10,4 & 13,3 & 14,0 & 12,1 & $\underline{16,0}$ & 13 & $\underline{7,1}$ & 0 & 1, & 6,2 & 5,7 & $\underline{34}$ & $\underline{28,7}$ & 13 & $\underline{13,4}$ & 5,5 & $\underline{12,7}$ \\
\hline 10 & 10 & 14,1 & 19,5 & $\underline{20,0}$ & 17,2 & $\underline{21,0}$ & 16,9 & $\underline{11,5}$ & 0,6 & 2,3 & 4,3 & 5,6 & $\underline{28,0}$ & $\underline{21,4}$ & 11,5 & $\underline{17,9}$ & 7,8 & $\underline{26,8}$ \\
\hline$\overline{0}$ & 20 & 56,0 & 60,9 & $\underline{61,1}$ & 58,2 & $\underline{67,1}$ & 54,3 & $\underline{56,6}$ & $\overline{11,1}$ & 24,9 & 17,0 & 19,4 & $\underline{52}$, & $\underline{46,0}$ & 31,0 & $\underline{53,5}$ & 27,2 & $\underline{64,2}$ \\
\hline 20 & 0 & 37,8 & , & $\underline{42}$, & 39,8 & 47,2 & 36,5 & $\underline{35,1}$ & 3 , & 10,1 & 10,9 & 11,9 & 42 & $\underline{37,2}$ & 22 & $\underline{\mathbf{3 4 , 0}}$ & 14,9 & 44,1 \\
\hline 20 & 20 & 52,8 & 53,6 & $\underline{\mathbf{5 8 , 6}}$ & 53,8 & $\underline{58,6}$ & 49,1 & $\underline{\mathbf{5 3 , 2}}$ & 8,4 & 22,6 & 8,1 & 11,9 & 34, & $\underline{\mathbf{2 7 , 4}}$ & 20,9 & $\underline{57,9}$ & 28,7 & $\underline{78,5}$ \\
\hline 20 & -20 & 92,0 & 93,4 & $\overline{92,0}$ & 93,4 & 96,0 & 88,5 & $\overline{94,4}$ & 54,4 & 76,8 & 69,9 & 66,9 & 90,0 & $\overline{92,6}$ & 79,7 & $\overline{92,1}$ & 73,5 & $\mathbf{9 4 , 5}$ \\
\hline 0 & 40 & 99,1 & 99,2 & 99,0 & 98,8 & $\mathbf{9 9 , 5}$ & 97,0 & $\underline{99,6}$ & 88,1 & 96,4 & 71,0 & 78,6 & 93. & $\underline{89,6}$ & 85 & 99,6 & 96,4 & $\overline{99,9}$ \\
\hline 40 & 0 & 93,2 & $\overline{4,3}$ & 93,6 & 93,7 & $\underline{96,1}$ & 87,2 & $\underline{95,1}$ & 58,4 & 78,9 & 45,3 & 52,0 & 79 , & $\underline{72,8}$ & 54,9 & $\underline{93,4}$ & 78,5 & 97,3 \\
\hline 40 & 40 & $\underline{98,7}$ & $\overline{98,4}$ & 98,2 & 97,7 & $\mathbf{9 8 , 5}$ & 94,7 & 99,1 & 78,5 & 92,9 & 45,7 & 60,2 & $\underline{\mathbf{8 2}, 1}$ & $\overline{71,2}$ & 70,1 & $\overline{99,2}$ & 94,3 & $1 \overline{100,0}$ \\
\hline 70 & 0 & 0,0 & $\underline{0,0}$ & 100,0 & 99,8 & 100,0 & 99,7 & 100,0 & 99,8 & 99,9 & 95,0 & 97,8 & 99 & 98,9 & 99, & $\underline{100,0}$ & 100,0 & 100,0 \\
\hline 0 & 70 & 100,0 & 0,0 & 100,0 & 99,2 & & 100,0 & $\overline{100,0}$ & 99,9 & 100, & 95,2 & 99,0 & 00 & 98,8 & 99, & 100,0 & 100,0 & 100, \\
\hline
\end{tabular}


Table 7 : Type one error estimate and power evaluation with respect to the dependence level

\begin{tabular}{|c|c|c|c|c|c|c|c|c|c|c|c|c|c|c|c|c|c|c|c|c|c|}
\hline$\delta_{\mathrm{Q}}$ & $\delta_{\mathrm{V}}$ & $\begin{array}{c}\mathrm{M} \\
\mathrm{SD}^{*}\end{array}$ & $\begin{array}{c}\mathrm{T} \\
\mathrm{TD} *\end{array}$ & $\begin{array}{c}\mathrm{W} \\
\mathrm{TD}^{*}\end{array}$ & $\begin{array}{l}\text { QIB } \\
\text { MD }\end{array}$ & $\begin{array}{l}\text { QIA } \\
\text { MD* }\end{array}$ & $\begin{array}{c}\mathrm{Z} \\
\mathrm{MD}^{*}\end{array}$ & $\mathrm{C}$ & $\begin{array}{c}\mathrm{M} \\
\mathrm{SD}^{*}\end{array}$ & $\begin{array}{c}\mathrm{T} \\
\mathrm{TD} *\end{array}$ & $\begin{array}{c}\mathrm{W} \\
\mathrm{TD} *\end{array}$ & $\begin{array}{l}\text { QIB } \\
\text { MD }\end{array}$ & $\begin{array}{l}\text { QIA } \\
\text { MD* }\end{array}$ & $\begin{array}{c}\mathrm{Z} \\
\mathrm{MD}^{*}\end{array}$ & $\mathrm{C}$ & $\begin{array}{c}\text { M } \\
\text { SD* }\end{array}$ & $\begin{array}{c}\mathrm{T} \\
\mathrm{TD}^{*}\end{array}$ & $\begin{array}{c}\mathrm{W} \\
\mathrm{TD} *\end{array}$ & $\begin{array}{l}\text { QIB } \\
\text { MD }\end{array}$ & $\begin{array}{c}\text { QIA } \\
\text { MD* }\end{array}$ & $\begin{array}{c}\mathrm{Z} \\
\mathrm{MD}^{*}\end{array}$ \\
\hline & & \multicolumn{7}{|c|}{ Estimated standard deviation } & \multicolumn{7}{|c|}{ Estimated standard deviation } & \multicolumn{6}{|c|}{ Estimated standard deviation } \\
\hline & & \multicolumn{7}{|c|}{$(\mathrm{n}, \mathrm{s})=(\mathbf{5 0 , 2 0})$} & \multicolumn{7}{|c|}{$(\mathrm{n}, \mathrm{s})=(\mathbf{5 0}, \mathbf{2 0})$} & \multicolumn{6}{|c|}{$(\mathrm{n}, \mathrm{s})=(\mathbf{5 0} 0,20)$} \\
\hline & & \multicolumn{7}{|c|}{$b=1.155($ with rho $=0.25)$} & \multicolumn{7}{|c|}{$b=1.414($ with rho $=0.50)$} & \multicolumn{6}{|c|}{$b=2.000($ with rho $=0.75)$} \\
\hline 0 & 0 & 4.9 & 3.4 & 2.4 & 0 & 11.3 & 5.2 & 4.1 & 5.4 & 4.6 & 3. & 6.8 & 12.4 & 5.8 & 5.4 & 4.7 & 3.9 & 3.0 & 6.3 & 11.5 & \\
\hline 0 & 10 & 13.8 & 12.0 & 12.9 & 2 & 12.5 & 6.6 & 15.9 & 14.8 & 13.6 & 14.2 & 6.9 & 10.4 & 7.7 & 15.3 & 20.8 & 19.8 & 21.9 & 10.2 & 17.7 & \\
\hline 10 & 0 & 10.6 & 9.0 & 8.7 & 3 & 11.3 & 6.6 & 11.1 & 10.5 & 9.5 & 9. & 6.7 & 9.7 & 7.3 & 10.1 & 15.9 & 15.6 & 15.5 & 7.7 & 13.9 & \\
\hline 10 & 10 & 17.3 & 14.8 & 15.3 & 5.9 & 10.0 & 9.4 & 21.6 & 12.8 & 11.4 & 11. & 4.9 & 7.6 & 8.2 & 19.5 & 13.9 & 13.1 & 13.1 & 5.7 & 10.8 & \\
\hline 0 & 20 & 41.6 & 38.0 & 46.9 & 17 & 21 & 19.4 & 50.7 & 47.8 & 46.5 & 54 & 17.6 & 22.9 & 24 & 50.4 & 70.1 & 71.7 & 82.2 & 34.2 & 47.2 & \\
\hline 20 & 0 & 27.9 & 26.4 & 30.3 & 10.4 & 17.1 & 12.3 & 33.9 & 31.8 & 29.4 & 34.9 & 11.7 & 15.5 & 13.2 & 31.9 & 48.6 & 51.0 & 57.3 & 21.5 & 32.1 & \\
\hline 20 & 20 & 53.1 & 48.9 & 60.9 & 14.1 & 21.5 & 29.4 & 71.9 & 46.0 & 42.8 & 53.6 & 11.3 & 15.2 & 26.3 & 67.4 & 42.6 & 38.4 & 47.8 & 11.0 & 18.1 & \\
\hline 20 & -20 & 68.2 & 68.5 & 79.6 & 41.2 & 55.0 & 42.5 & 80.1 & 83.4 & 85.7 & 92.3 & 61.6 & 68.9 & 64.7 & 87.0 & 97.3 & 98.6 & 99.7 & 89.7 & 94.5 & \\
\hline 0 & 40 & 94.2 & 92.5 & 97.8 & 58.7 & 69.5 & 84.1 & 99.0 & 97.5 & 97.6 & 99.4 & 77.1 & 82.2 & 94.2 & 99.4 & 99.9 & 99.5 & 100 & 95.8 & 97.9 & \\
\hline 40 & 0 & 80.7 & 77.8 & 88.8 & 36.2 & 47.3 & 56.9 & 90.9 & 87.9 & 87.4 & 94.3 & 49.8 & 56.8 & 69.1 & 93.6 & 97.3 & 97.9 & 99.6 & 79.5 & 86.2 & \\
\hline 40 & 40 & 97.7 & 96.7 & 99.2 & 62.6 & 71.3 & 95.0 & 100 & 96.9 & 95.4 & 99.4 & 55.0 & 61.1 & 90.9 & 99.9 & 94.7 & 91.8 & 97.5 & 52.6 & 62.1 & 84.8 \\
\hline 70 & 0 & 99.8 & 99.3 & 100 & 91 & 94.4 & 99.2 & 100 & 100 & 99.5 & 10 & 98. & 98.9 & 10 & 100 & 100 & 97.7 & 100 & 99.9 & 100 & \\
\hline 70 & 70 & 100 & 97.6 & 100 & 99.0 & 99.7 & 100 & 100 & 100 & 98.8 & 100 & 99.1 & 99.4 & 100 & 100 & 100 & 98.8 & 100 & 97.6 & 98.7 & \\
\hline
\end{tabular}


Table 8 : General information about the Moisie, Magpie and Romaine stations.

\begin{tabular}{lccccc}
\hline $\begin{array}{l}\text { Station } \\
\text { name }\end{array}$ & $\begin{array}{c}\text { Station } \\
\text { number }\end{array}$ & Latitude & Longitude & $\begin{array}{c}\text { Period of } \\
\text { record } \\
\text { (\#years) }\end{array}$ & $\begin{array}{c}\text { Area } \\
\left(\mathbf{K m}^{\mathbf{2}}\right)\end{array}$ \\
\hline Moisie & 072301 & 502109 & -661112 & $1968-1998(31)$ & 19012 \\
Magpie & 073503 & 504108 & -643443 & $1979-2004(26)$ & 7201 \\
Romaine & 073801 & 501828 & -633707 & $1961-2006(46)$ & 12922 \\
\hline
\end{tabular}

Table 9 : Test statistics and p-values of M-, T-, QIB-, QIA-, Z- and C-test and

decision (1: shift, 0 : no shift) of W-test.

\begin{tabular}{|c|c|c|c|c|c|c|c|c|c|c|c|c|c|c|c|c|}
\hline \multirow{2}{*}{\multicolumn{2}{|c|}{ Tests }} & \multicolumn{3}{|c|}{$\mathbf{M}$} & \multicolumn{3}{|c|}{$\mathbf{T}$} & \multicolumn{3}{|c|}{$\mathbf{W}$} & \multicolumn{2}{|l|}{ QIB } & \multicolumn{2}{|c|}{ QIA } & \multirow{2}{*}{\begin{tabular}{|c|}
$\mathrm{Z}$ \\
TD $\mathrm{MD} *$
\end{tabular}} & \multirow{2}{*}{ Cramer } \\
\hline & & TD & MD & SD* & TD* & MD & SD & TD* & MD & SD & TM MD* & SD & TD & MD* & & \\
\hline \multicolumn{17}{|c|}{ a) Without standardizing the samples } \\
\hline \multirow{2}{*}{ Moisie } & Stat & 0.08 & 0.00 & 0.00 & 0.32 & 0.10 & 0.19 & 0.22 & 0.06 & 0.06 & 0.100 .06 & 0.00 & 0.10 & 0.06 & 16.020 .5 & 9353.21 \\
\hline & p-val & 0.00 & 0.01 & 0.05 & 0.00 & 0.00 & 0.00 & 1 & 1 & 1 & 0.000 .00 & 0.00 & 0.00 & 0.00 & 0.000 .00 & 0.00 \\
\hline \multirow{2}{*}{ Magpie } & Stat & 0.30 & 0.00 & 0.00 & 0.60 & 0.20 & 0.30 & 0.5 & 0.3 & 0.3 & $0.3 \quad 0.19$ & 0.00 & 0.30 & 0.19 & $\begin{array}{|ll|}0.99 & 2.92\end{array}$ & 1132.50 \\
\hline & p-val & 0.16 & 0.54 & 0.53 & 0.08 & 0.09 & 0.07 & 0 & 0 & 0 & $0.47 \quad 0.32$ & 0.02 & 0.11 & 0.02 & 0.320 .09 & 0.03 \\
\hline \multirow{2}{*}{ Romaine } & Stat & 0.50 & 0.10 & 0.10 & 0.70 & 0.30 & 0.30 & 0.63 & 0.50 & 0.60 & $\begin{array}{lll}0.40 & 0.31\end{array}$ & 0.10 & 0.40 & 0.31 & 2.504 .08 & 2478.40 \\
\hline & p-val & 0.03 & 0.07 & 0.07 & 0.03 & 0.09 & 0.19 & 0 & 1 & 1 & $\begin{array}{|ll|}0.10 & 0.11 \\
\end{array}$ & 0.04 & 0.05 & 0.01 & $\begin{array}{|ll|}0.11 & 0.04 \\
\end{array}$ & 0.01 \\
\hline \multicolumn{17}{|c|}{ b) With standardizing the samples } \\
\hline \multirow{2}{*}{ Moisie } & Stat & 0.07 & 0.00 & 0.00 & 0.31 & 0.10 & 0.20 & 0.21 & 0.05 & 0.04 & 0.090 .04 & 0.00 & 0.09 & 0.04 & 17.121 .2 & 9.13 \\
\hline & p-val & 0.00 & 0.03 & 0.03 & 0.00 & 0.00 & 0.00 & 1 & 1 & 1 & 0.000 .00 & 0.00 & 0.00 & 0.00 & 0.000 .00 & 0.00 \\
\hline \multirow{2}{*}{ Magpie } & Stat & 0.26 & 0.00 & 0.00 & 0.54 & 0.18 & 0.22 & 0.45 & 0.24 & 0.21 & 0.240 .13 & 0.00 & 0.24 & 0.13 & $\begin{array}{|ll|}2.47 & 5.74 \\
\end{array}$ & 3.19 \\
\hline & p-val & 0.06 & 0.34 & 0.38 & 0.02 & 0.04 & 0.01 & 0 & 1 & 1 & 0.180 .09 & 0.01 & 0.03 & 0.00 & $\begin{array}{ll}0.12 & 0.02\end{array}$ & 0.00 \\
\hline \multirow{2}{*}{ Romaine } & Stat & 0.47 & 0.08 & 0.06 & 0.68 & 0.24 & 0.24 & 0.58 & 0.44 & 0.52 & \begin{tabular}{|lll}
0.35 & 0.31
\end{tabular} & 0.13 & 0.35 & 0.31 & 3.375 .64 & 4.53 \\
\hline & p-val & 0.02 & 0.04 & 0.05 & 0.01 & 0.01 & 0.05 & 1 & 1 & 1 & $\begin{array}{lll}0.09 & 0.07\end{array}$ & 0.02 & 0.04 & 0.01 & $\begin{array}{ll}0.07 & 0.02\end{array}$ & 0.00 \\
\hline
\end{tabular}




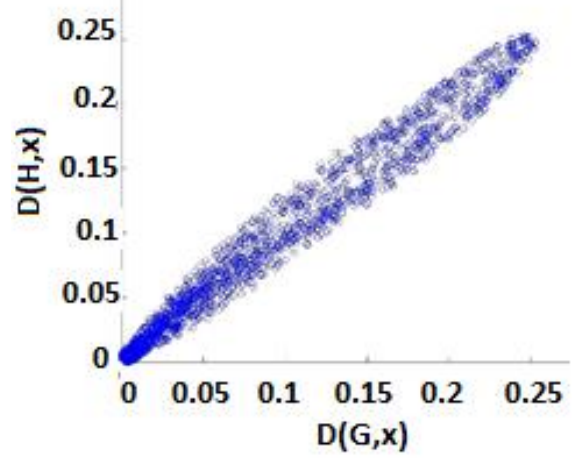

a)

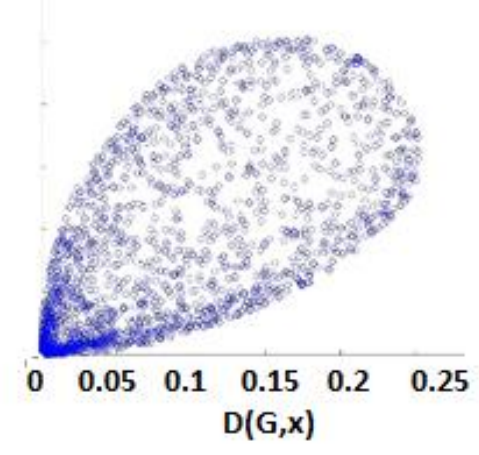

b)

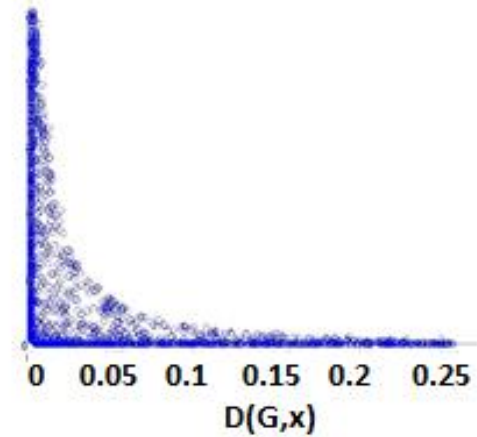

c)

Figure 1 : DD-plot for a) two identical subsamples, b) two different subsamples and c) two very different subsamples. 


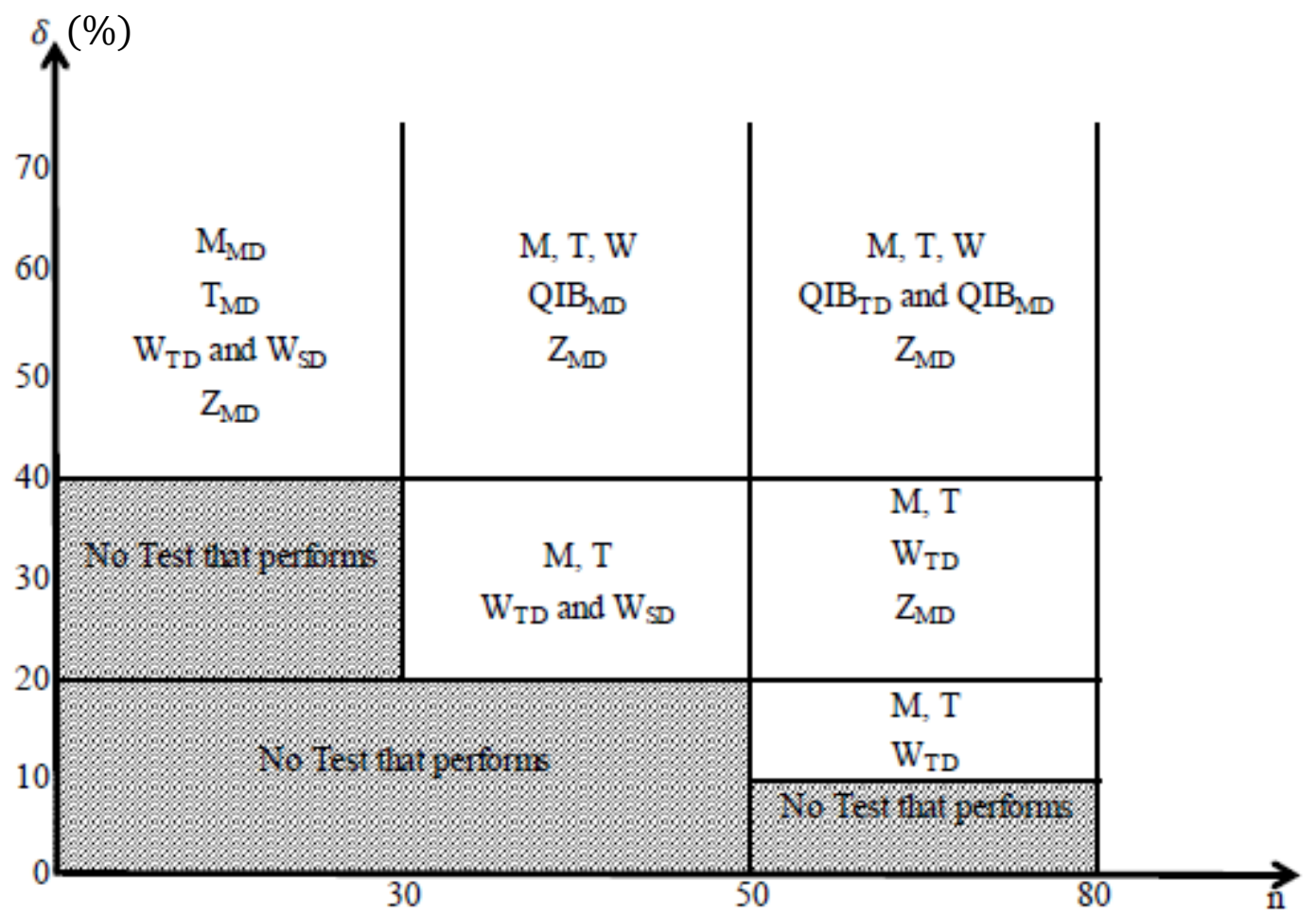

Figure 2 : Diagram of the applicability of considered tests for studied sample lengths $(n)$ and shift amplitudes $(\delta)$. 


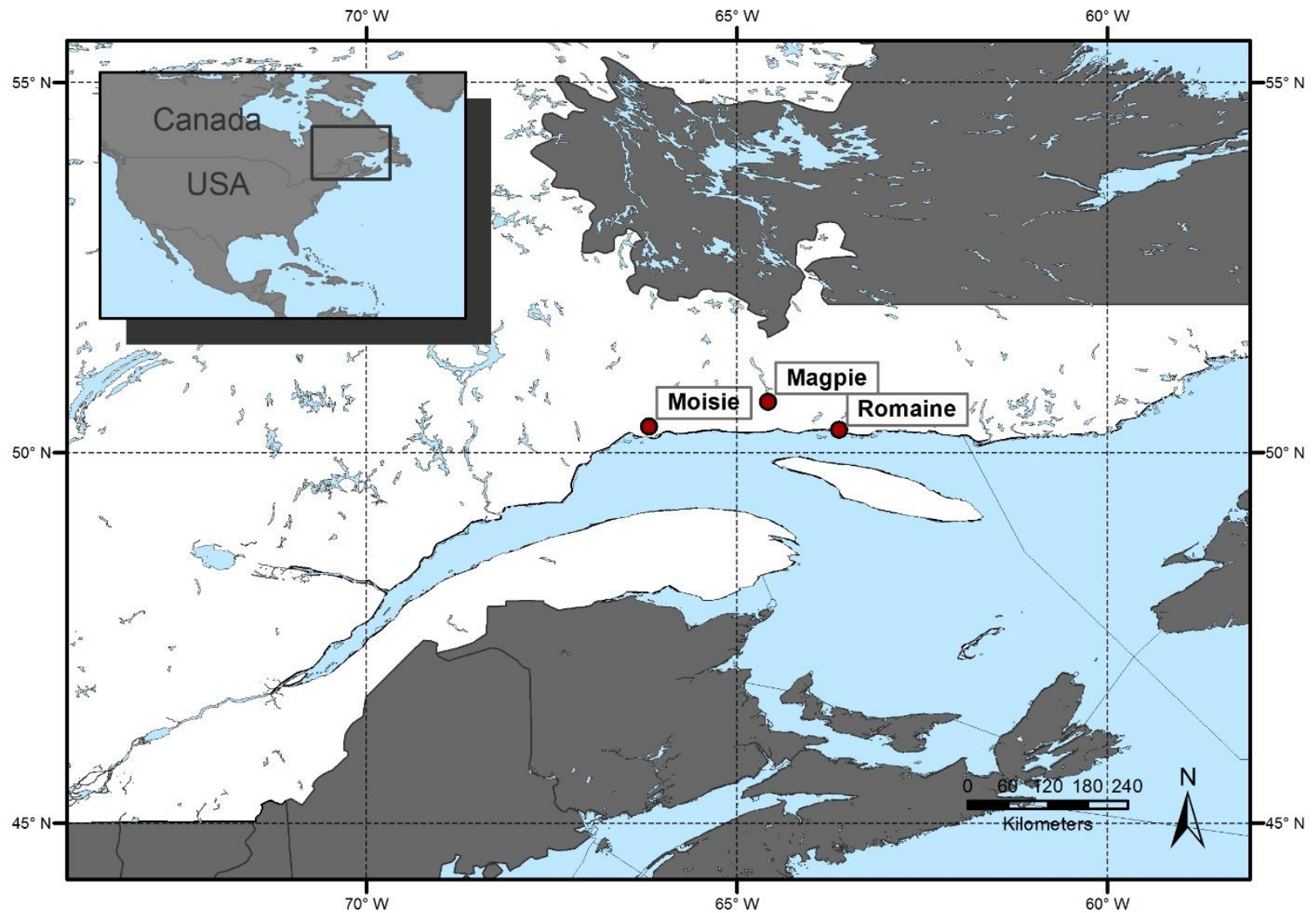

Figure 3 : Geographical location of the Moisie, Magpie and Romaine stations. 
a)
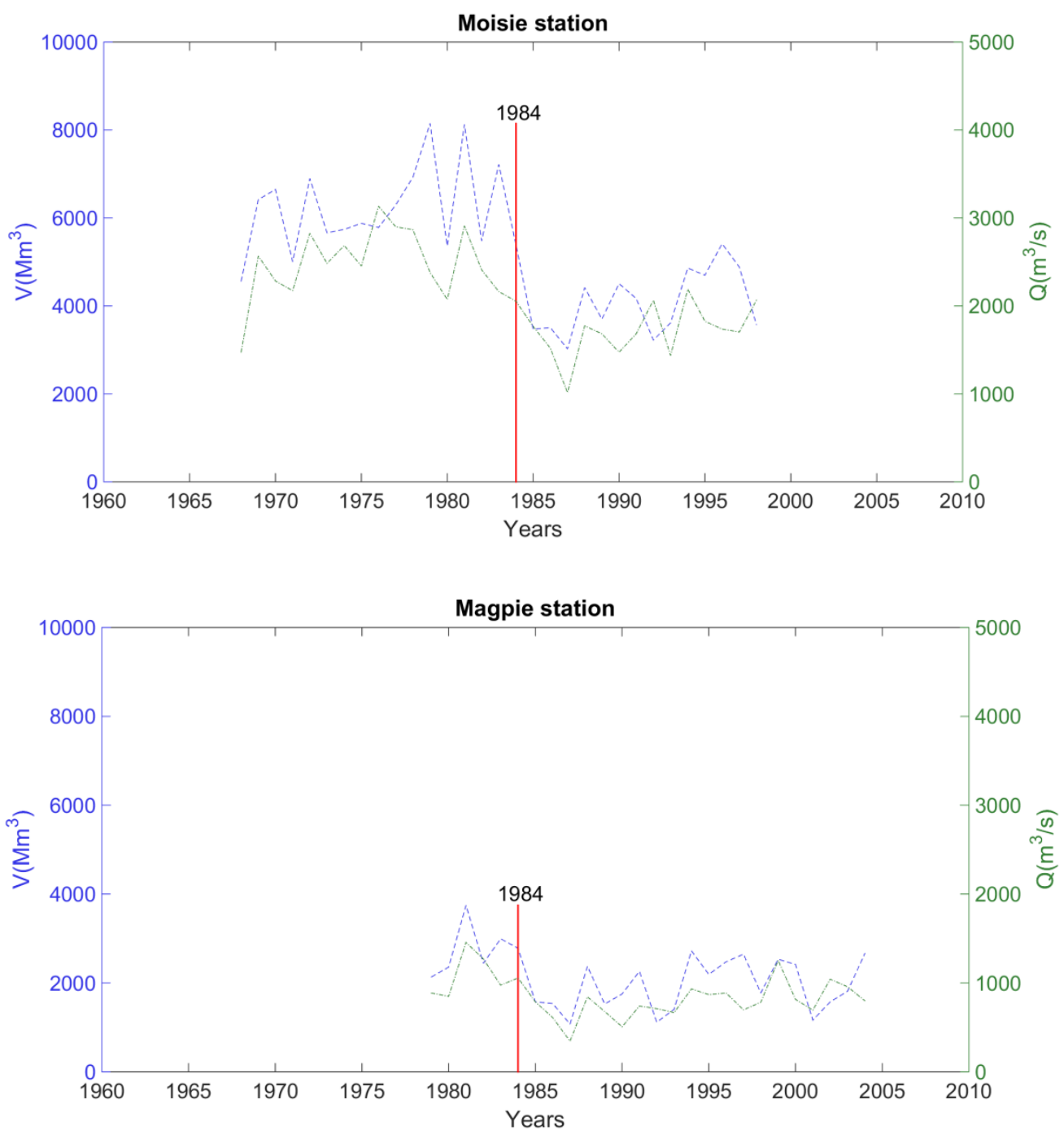

b)

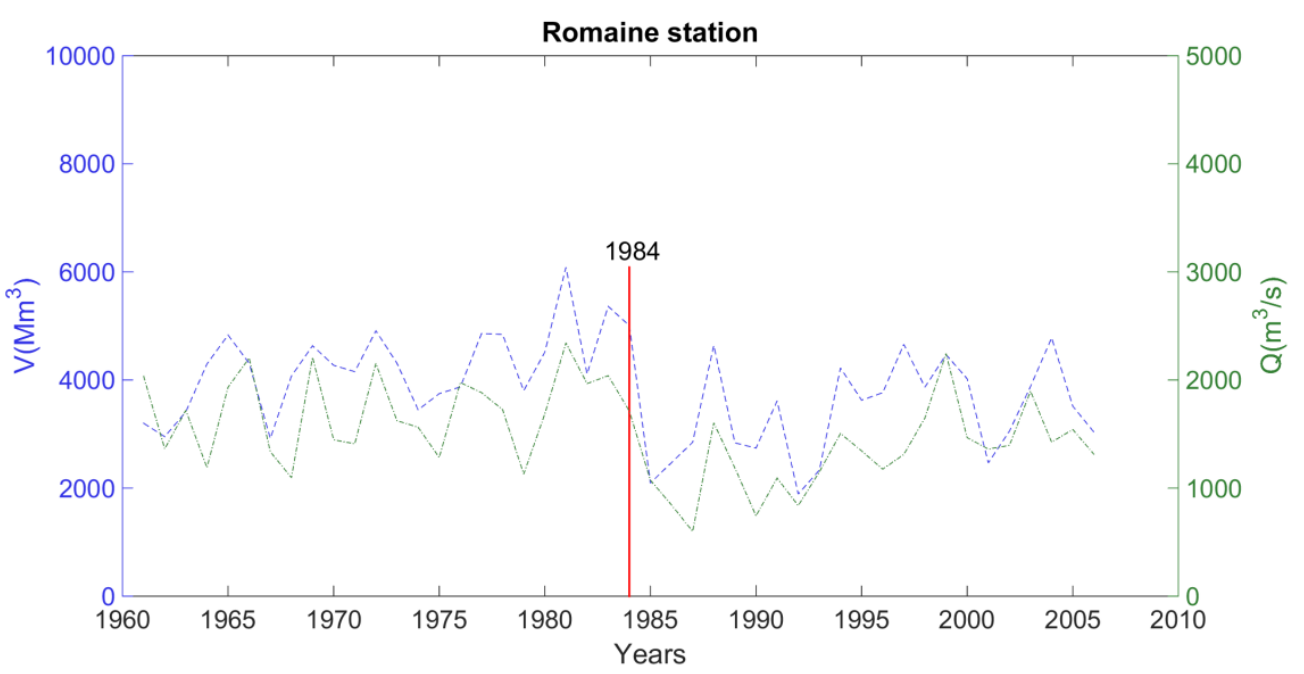

Figure 4 : The $V$ and $Q$ time series of a) Moisie, b) Magpie and c) Romaine stations. 